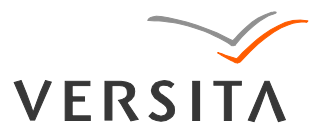

GEOCHRONOMETRIA 41(1) 2014: 36-56

DOI 10.2478/s13386-013-0140-7

Available online at

www.springerlink.com

\title{
OPTICALLY STIMULATED LUMINESCENCE DATING OF YOUNG FLUVIAL DEPOSITS OF THE MIDDLE ELBE RIVER FLOOD PLAINS USING DIFFERENT AGE MODELS
}

\author{
ALEXANDER KUNZ ${ }^{1,2}$, DORTHE PFLANZ ${ }^{1,3}$, TOBIAS WENIGER ${ }^{4}$, BRIGITTE URBAN $^{5}$, \\ FRANK KRÜGER ${ }^{5}$ and YUE-GAU CHEN ${ }^{1}$ \\ ${ }^{I}$ Department of Geosciences, National Taiwan University, No.1, Sec.4, Roosevelt Road, Taipei 10617, Taiwan (R.O.C.) \\ ${ }^{2}$ Section S3: Geochronology and Isotope Hydrology, Leibniz Institute for Applied Geophysics, Stilleweg 2, 30655 Hannover, Germany \\ ${ }^{3}$ Institute of Applied Geosciences, Technische Universität Darmstadt, Schnittspahnstr. 9, 64287 Darmstadt, Germany \\ ${ }^{4}$ Environmental protection office in Saxony-Anhalt, Reideburger Strasse 47, 06009 Halle (Saale), Germany \\ ${ }^{5}$ Institute of Ecology, Subject Area Landscape Change, Leuphana University, Scharnhorststrasse 1, 21355 Lüneburg, Germany
}

Received 7 January 2013

Accepted 25 September 2013

\begin{abstract}
In the last few decades optically stimulated luminescence (OSL) dating has become an important tool in geochronological studies. The great advantage of the method, i.e. dating the depositional age of sediments directly, can be impaired by incomplete bleaching of grains. This can result in a scattered distribution of equivalent doses $\left(\mathrm{D}_{\mathrm{E}}\right)$, leading to incorrect estimation of the depositional age. Thoroughly tested protocols as well as good data analysis with adequate statistical methods are important to overcome this problem. In this study, samples from young fluvial sand and flood plain deposits from the Elbe River in northern Germany were investigated to compare its depositional ages from different age models with well-known historical dates. Coarse grain quartz $(100-200 \mu \mathrm{m}$ and $150-250 \mu \mathrm{m})$ and polymineral fine grains $(4-11 \mu \mathrm{m})$ were dated using the single aliquot regenerative (SAR) dose protocol. The paleodose $\left(\mathrm{D}_{\mathrm{P}}\right)$ was calculated from the $\mathrm{D}_{\mathrm{E}}$ data set using different approaches. Results were compared with the development of the Elbe River, which is well-documented by historical records and maps covering the last 1,000 years. Depending on the statistical approach it can be demonstrated that depositional ages significantly differ from the most likely depositional age. For the investigated coarse grain quartz samples all ages calculated from the MAM-3 $3_{\mathrm{UL}}$, including their uncertainties, are within the historical documented age. Results of the polymineral fine grain samples are overestimating the historically documented depositional age, indicating undetectable incomplete bleaching. This study shows the importance of using an adequate statistical approach to calculate reliable OSL ages from fluvial sediments.
\end{abstract}

Keywords: optically stimulated luminescence dating, fluvial sand, age model, Elbe River floodplain, North Germany. 


\section{INTRODUCTION}

In the context of the ongoing KLIMZUG-NORD project, several studies were conducted in 'The Biosphere Reserve Niedersächsische Elbtalaue' (Lower Saxonian Elbe Valley) with the aim of investigating the impact of climatic changes on the landscape evolution (cultural and natural). One target of the KLIMZUG-NORD project is the development of strategies for adaption to climatic changes with concepts for sustainable land use as well as protection of landscape and natural habitats. Accompanying these studies, samples for OSL dating have been taken to investigate the timing of flood plain deposition and soil development along the Middle Elbe River (Urban et al., 2011a).

The OSL dating method has been developed over the last three decades and routine application to date sediments from different geological environments, e.g. aeolian, fluvial, marine and glacial is common. In recent years, dating of fluvial deposits with OSL has become more important because of the advantage of directly determining the time elapsed since deposition, therefore indirect dating with radiocarbon dating or other methods can be avoided (e.g. Wallinga et al., 2010; Wallinga and Bos, 2010). A descriptive review of the application of OSL dating on fluvial deposits is given in Wallinga (2002) and Rittenour (2008).

Despite the advantages of using OSL dating on fluvial deposits, the sediments deposited by fluvial processes often have the problem of incomplete bleaching of grains. During fluvial transport grains might not be fully bleached under turbid water conditions, with events having short or rapid transportation, or transport in deep water which attenuates most of the incoming solar radiation (Dietlefsen, 1992; Rendell et al., 1994). After deposition and during burial the OSL signal builds up again adding to a remnant signal resulting in age overestimation. The incomplete and non-uniform bleaching of grains under this depositional environments may result in a wide distribution of equivalent doses $\left(\mathrm{D}_{E}\right)$ making the estimation of the true depositional age difficult using OSL dating method (Fiebig and Preusser, 2007; Duller, 2008).

In recent years, different approaches have been developed to deal with scattered $\mathrm{D}_{\mathrm{E}}$ distributions from partially bleached sediments. Most of them were developed for a specific set of samples or based on subjective criteria (e.g., Murray et al. (1995), the lowest $x \%$ method from Olley et al. (1998), Fuchs and Lang (2001)). Whereas the leading edge model from Lepper and McKeever (2002), the central age model (CAM) and minimum age models (MAM) from Galbraith et al. (1999) and the unlogged counterparts from Arnold et al. (2009) are objective and mathematically unambiguous approaches. The logged and unlogged CAM and MAM are currently the most suitable age models for equivalent dose calculation (Galbraith and Roberts, 2012). These models are based on a well-specified statistical basis and there suitability has been approved in empirical and modeling studies (e.g. Olley et al., 2004; Bailey and Arnold, 2006; Arnold et al., 2009). A recent review of statistical aspects of equivalent dose calculation in OSL dating was given in Galbraith and Roberts (2012).

Based on the historically well-documented development, land use and hydro engineering impact on the Elbe River in North Germany, this place is ideal for comparison of different statistical methods for OSL dating of fluvial sediments. For this reason, two sections were sampled for OSL dating. The depositional ages were calculated using the CAM, MAM and their unlogged counterparts, the leading edge model and the approach from Fuchs and Lang (2001). The aim of this study is to demonstrate the differences in ages due to the application of different statistical methods or age models. The comparison of the obtained ages with the historicallydocumented river evolution will give indication about the most suitable age model in obtaining reliable results.

\section{STUDY AREA}

\section{Regional setting}

The study area is located at the Elbe River (river kilometer 513 to 515) around $90 \mathrm{~km}$ southeast of Hamburg close to the village Wehningen in North Germany (Fig. 1a and 1b). With $1094 \mathrm{~km}$ length and 148,268 $\mathrm{km}^{2}$ catchment area, the Elbe River is one of the major rivers in Europe (IKSE). The course of the Elbe River changed significantly during the last Quaternary glaciations of Northern Europe. The pre-glacial (Late Neogene) river course was very likely in a northern direction from the German/Czech border passing Berlin into the Baltic Sea (Woldstedt, 1956; Genieser, 1962). Due to the extent of the Scandinavian ice sheet in Germany during the Elsterian (MIS 12), Saalian (MIS 6 to 8) and Weichselian (MIS 2 to 4) glaciations, the drainage pattern of the river changed to a northwestern direction. During periods of ice retreat, the Elbe River changed its course and almost followed the old pathway to the north (Woldstedt, 1956). In northern Germany the present river course developed during the maximum extent of the Weichselian ice sheet between 22,000 and 18,000 years BP (Ehlers et al., 2007). The flow to the Baltic Sea was blocked and in front of the ice sheet the Elbe Urstromtal developed which is now the drainage valley of the Elbe River. Since the beginning of the $19^{\text {th }}$ century, the German part of the Elbe River has been massively influenced by human activities. River engineering was intensified to make the river navigable as well as to control floods and drift ice (Rommel et al., 2012).

The Elbe River is a meandering river. Remnants of previous meanders like oxbow lakes or abandoned river arms are still visible (Fig. 1c). The area under investigation is located in the Middle Elbe flood plain and has an area of approximately 140 ha. Based on the evolution of 


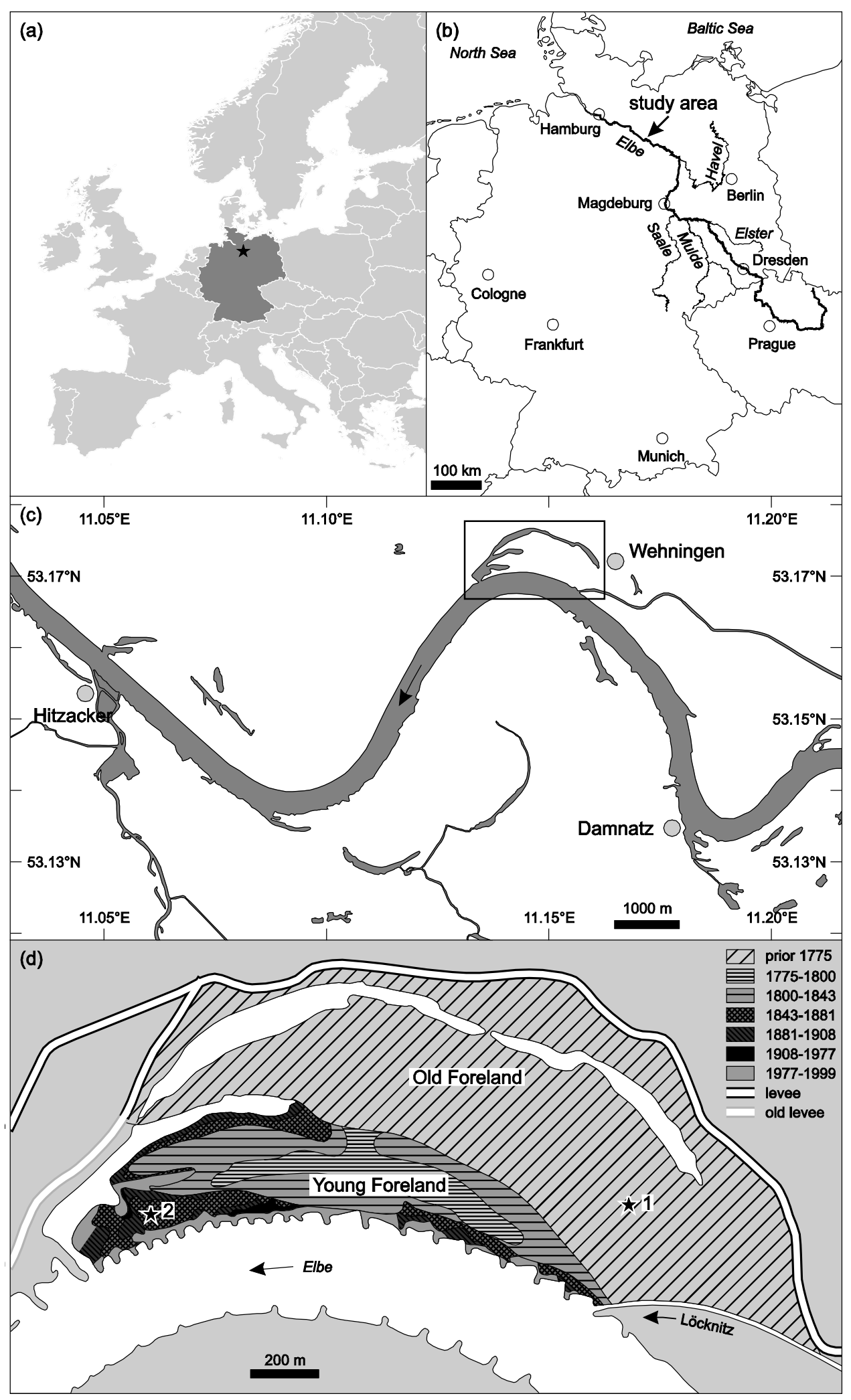

Fig. 1. Maps showing (a) the location of the study area in Germany; (b) Course of the Elbe River with its major tributaries; (c) Elbe River between Damnatz and Hitzacker. The rectangle marks the location of the study area; (d) Detailed map of the study area in Wehningen. Stars with numbers indicate the position of investigated sections (1 = section 1; 2 = section 2). Land gained through river engineering from the year $1775 \mathrm{AD}$ to the present state is shown by different shades of grey and hatching as well as cross-hatching (map redrawn and modified from Weniger, 2010). Old Foreland refers to the area developed prior to $1775 A D$ and the Young Foreland developed after $1775 A D$. 
this area, it can be subdivided into an older part called 'altes Vorland' (Old Foreland) and a younger part called 'junges Vorland' (Young Foreland) (Weniger, 2010). The Old Foreland developed during the natural change of the meander to a more southward position. An abandoned river arm in the northern part indicates the former position of the active river channel. The development of the Younger Foreland is due to human activities. At the end of the $18^{\text {th }}$ century river engineering activities started in this area. Due to the use of gabions, fascines and construction of groins, new land was gained and as a result, the river moved about $400 \mathrm{~m}$ to the south (Fig. 1d). The present riverbed is kept in a fixed position with groins, which are constructed in such a way that erosion and sedimentation along the riverbanks are mostly equal.

Two sections have been investigated and sampled for OSL dating, one located in the Old Foreland (section 1) and the other in the Young Foreland (section 2) (Fig. 1d). Section 1 (Fig. 2) is located in the eastern part of the study area on a plateau. With an elevation of $13.7 \mathrm{~m}$ above the present sea level and $2.3 \mathrm{~m}$ above the mean water level of the river this area represents the higher elevated part of the Old Foreland. The section was excavated to a depth of $1 \mathrm{~m}$. The basal part is built of medium to fine grained fluvial sand. Drillings show that this sand continues to a depth of at least $2 \mathrm{~m}$ below the surface. The sand appears homogenous with no apparent sedimentological structures. The upper part of the section is comprised of a $78 \mathrm{~cm}$ thick floodplain deposit which is mostly silty sand. The uppermost $17 \mathrm{~cm}$ of the floodplain deposit is sandy loam. The transition between the floodplain deposit and the sand is characterized by a $15 \mathrm{~cm}$ thick unit of alternating sand and silt layers. From section 1 , two samples for OSL dating were collected, one from the floodplain deposit (WEH1-1) and one from the basal fluvial sand (WEH1-2).

Section 2 (Fig. 3) is located in the western part of the study area at an elevation of $12.9 \mathrm{~m}$ above present sea

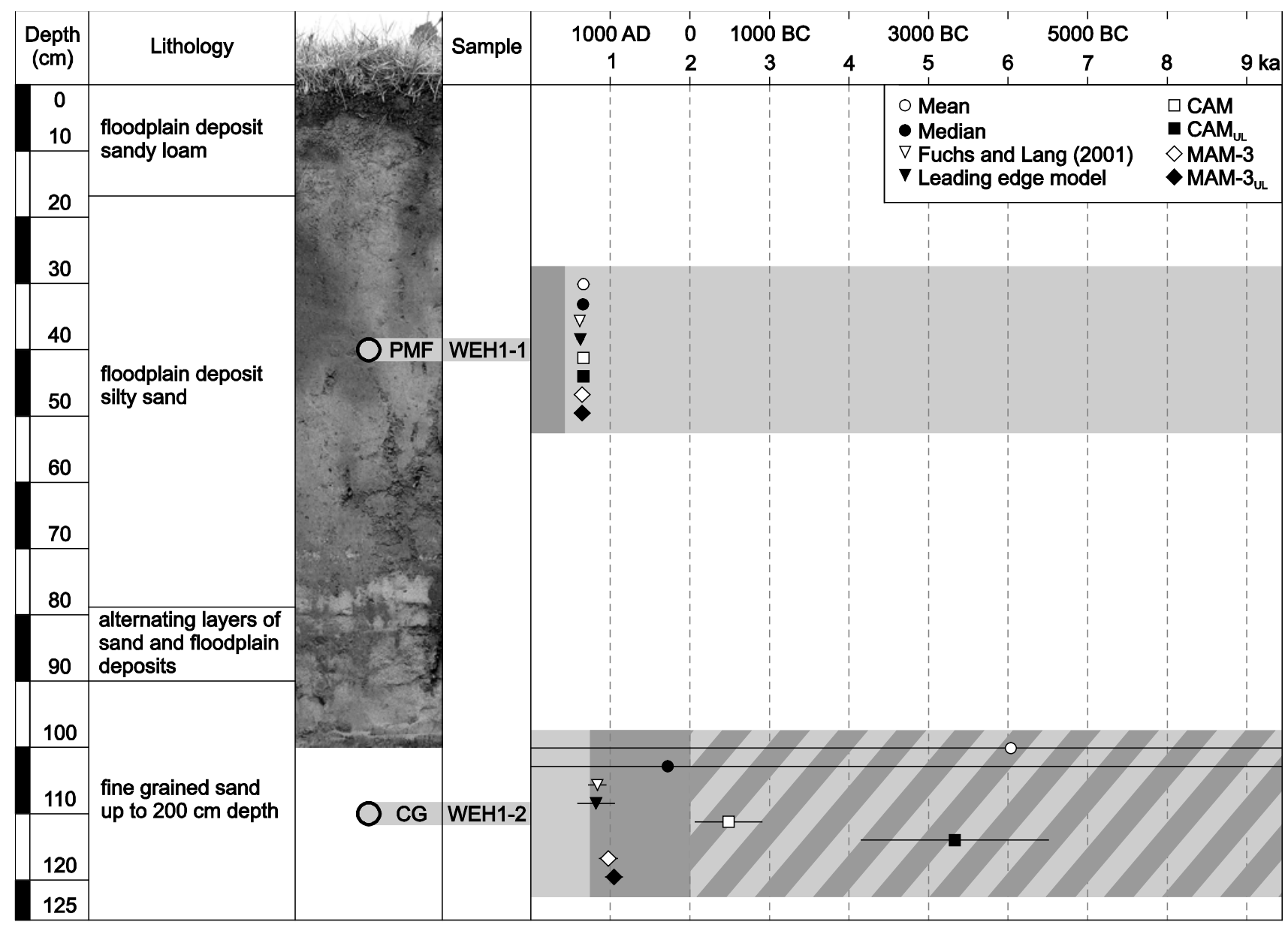

Fig. 2. Section 1 located on the Old Foreland. For each sample the OSL ages from different age models are shown. For numerical values the reader is referred to table 5 and 6. Dark grey marked areas indicate the documented time period of deposition which is derived from historical maps and written records. For the lowermost sand layer (WEH1-2) no historical records older than 800 AD are available. A maximum age of deposition cannot be given here. Hatched area shows a period were sand deposition could be possible. $P M F=$ polymineral fine grain, $C G=$ coarse grain. (Photograph of section from Weniger, 2010). 
level in the Younger Foreland. The section was excavated to a depth of $1.3 \mathrm{~m}$. The basal part is built of medium grained fluvial sand. Drillings show that the sand continues to a depth of at least $2 \mathrm{~m}$ below surface. The upper part of the investigated section is mostly a loamy and silty floodplain deposit with intercalated 1 to $5 \mathrm{~cm}$ thick layers of medium grained sand. The contact between the sand layers and the floodplain deposit is sharp. From section 2, five samples were collected; three from the fluvial sand (WEH2-2, WEH2-4 and WEH2-5) and two samples were taken from the floodplain deposit (WEH2-1 and WEH2-3).

\section{Historical evolution of the Elbe River in the study area}

The anthropogenic impact on the landscape happened at different times and by different activities such as building of dams and founding settlements. Wehningen began to be populated in $1158 \mathrm{AD}$ (Fabel, 2001), and three years later in the year $1261 \mathrm{AD}$ a first dam was constructed to protect the village from floods (Puffahrt, 1999). The location of this dam was approximately along a levee which is today the border between the Old Foreland and the Young Foreland (Fig. 1d). This dam prevented flooding and new sedimentation of sand in the area where

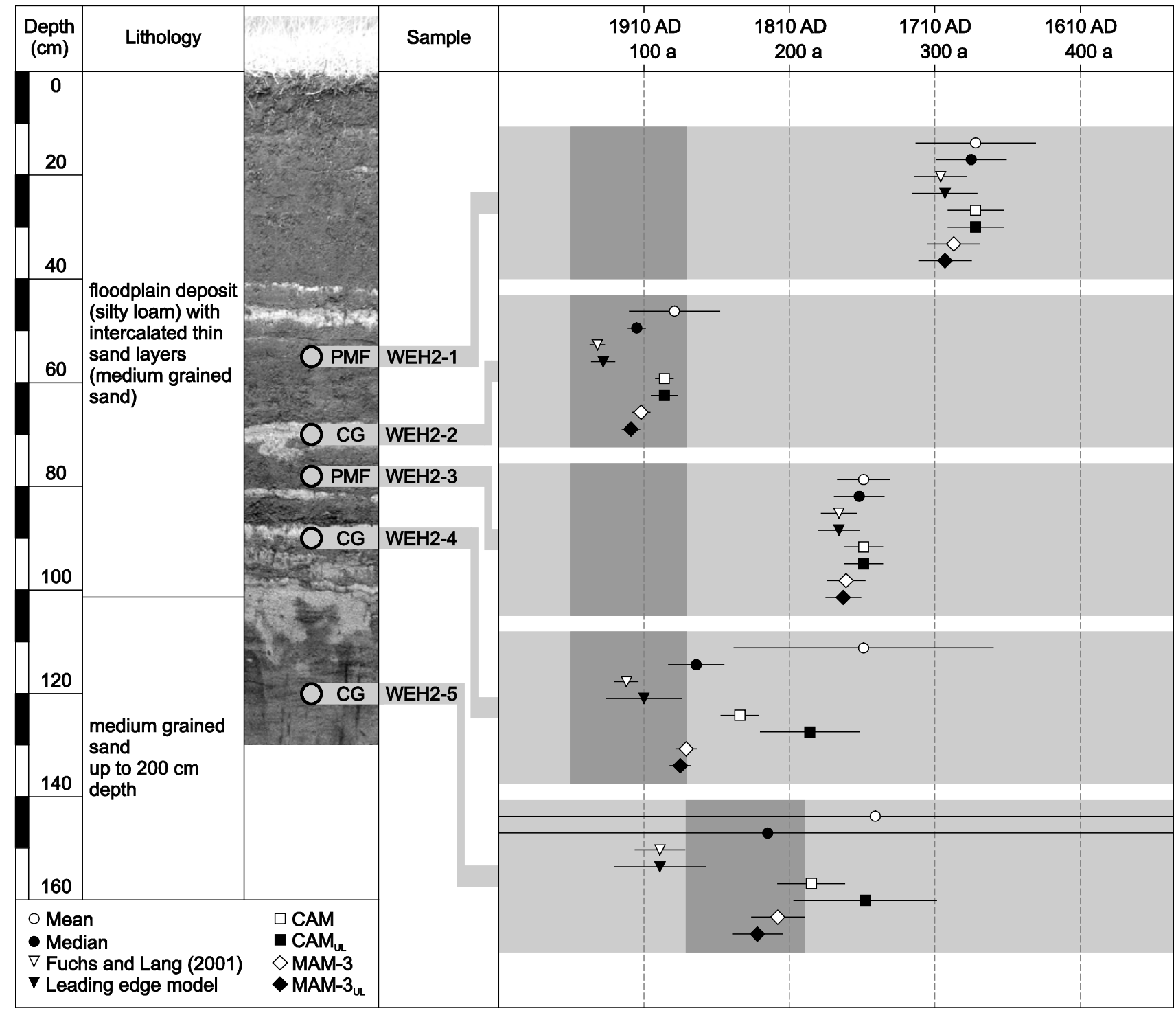

Fig. 3. Section 2 located on the Young Foreland. For each sample, OSL ages from different age models are shown. For numerical values the reader is referred to Tables 5 and 6. Dark grey marked areas indicate the documented time period of deposition which is derived from historical maps and written records. $P M F=$ polymineral fine grain, $C G=$ coarse grain. (Photograph of section from Weniger, 2010). 
section 1 is located. The age of deposition for sample WEH1-2 should therefore be older than 749 years (all ages mentioned here are related to the year of sampling in $2010 \mathrm{AD}$ ). Due to the lack of historical records older than the year $800 \mathrm{AD}$ the position of the river cannot be reconstructed beyond this point.

In the year $1590 \mathrm{AD}$ the old dam was demolished and a new dam was constructed close to the present dam location (Greve, 1999). From this time the area where section 1 is located could be flooded and deposition of sediment was possible. Hence, the upper part of the floodplain deposit should be younger than 420 years (Fig. 2). It is likely that the lower part of the floodplain deposit in this section is older than 420 years. But there is no visible unconformity in the sedimentary record to distinguish this.

The young foreland, where section 2 is located, developed since $1775 \mathrm{AD}$ due to intensified river management (Weniger, 2010). On historical maps from $1726 \mathrm{AD}$ and $1775 \mathrm{AD}$ it is clearly visible that at the position where section 2 is located was an active river channel (Fig. 4). Due to construction of fascines and groins, new land was gained successively. In the time period from $1843 \mathrm{AD}$ to $1881 \mathrm{AD}$ the area of section 2 finally became land (Figs. 1d and 4). Based on this development, the depositional age of sample WEH2-5 from the sand at the base in section 2 should be between 129 years and 210 years old. For the floodplain deposit with the intercalated sand layers, an age younger than 129 years can be expected. An ongoing study of heavy metal distribution in the flood plain deposit of section 2 shows increased concentrations of $\mathrm{Hg}$ at a depth of 30-40 cm $(\max .19 \mathrm{mg} / \mathrm{kg}$ $\mathrm{Hg}$ ) and a second peak at a depth of about $15 \mathrm{~cm}$ (max. $15 \mathrm{mg} / \mathrm{kg} \mathrm{Hg}$ ). The first peak corresponds with the years 1950-1960 AD, a period of heavy pollution of the river with dioxin, $\mathrm{Hg}$ and other heavy metals (Urban et al., 2011a; Götz et al., 2007). And the second peak corresponds with the year 1980 AD where again heavy pollution with $\mathrm{Hg}$ in the Elbe River occurred (Urban et al., 2011a). Based on these data the depositional age of samples WEH2-1, WEH2-2, WEH2-3 and WEH 2-4 may fall between 50 and 129 years ago (Fig. 3).

\section{OPTICALLY STIMULATED LUMINESCENCE DATING}

\section{Paleodose estimation}

Samples for OSL dating were collected using opaque plastic tubes. After cleaning the section, the tubes were hammered into the wall. The samples were prepared in the Luminescence Laboratory at the Section S3: Geochronology and Isotope Hydrology in the Leibniz Institute for Applied Geophysics in Hannover (Germany). In the laboratory the tubes were opened under subdued red light and the light-exposed outer parts from each side of the tubes were removed. The remaining material passed through the standard sample preparation procedures for

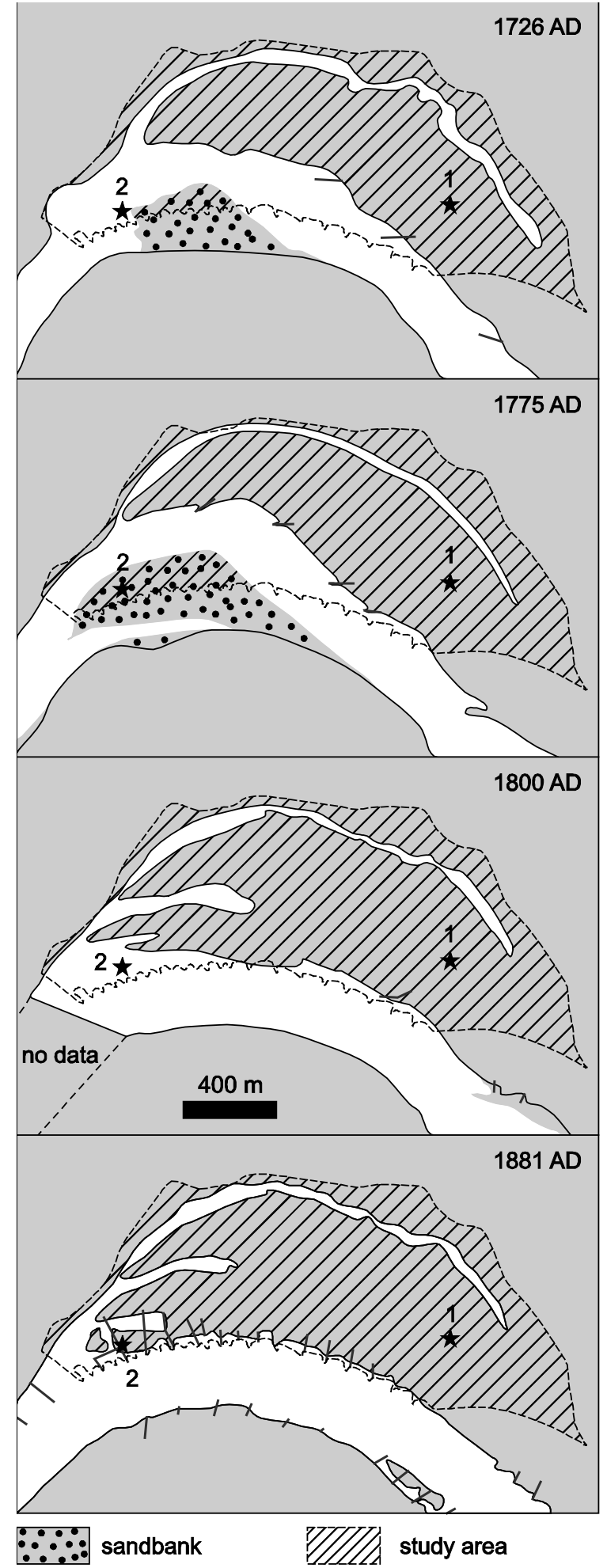

Fig. 4. Relocation of the Elbe River in the study area from $1726 A D$ to $1881 A D$. In $1775 A D$ the extent of the sandbank reached the position of section 2. But later in $1800 A D$ the sandbank was eroded and earlier deposited sand was very likely removed. Latest since 1881 AD the position at section 2 became land. Maps are redrawn from historical maps which are cited in the reference list. Stars showing the position of the investigated sections (1 = section 1; 2 = section 2). Short black lines along the river bank are groins. 
OSL dating including dry sieving, removal of carbonates using hydrochloric acid $(\mathrm{HCl})$, removal of organic material using hydrogen peroxide $\left(\mathrm{H}_{2} \mathrm{O}_{2}\right)$, and density separation using sodium polytungstate $\left(\mathrm{Na}_{6}\left[\mathrm{H}_{2} \mathrm{~W}_{12} \mathrm{O}_{40}\right]\right)$ as heavy density liquid with $2.62 \mathrm{~g} \mathrm{~cm}^{-3}$ and $2.70 \mathrm{~g} \mathrm{~cm}^{-3}$ density. The quartz fraction was etched with concentrated hydrofluoric acid (40\% HF) for 60 minutes to remove feldspar and the outer layer of the grains which is affected by $\alpha$-radiation. The remaining material was re-sieved to remove damaged grains. The purified quartz fraction with a grain size from $100-200 \mu \mathrm{m}$ and $150-250 \mu \mathrm{m}$ was used for OSL dating. Quartz grains were mounted using silicon oil (Rüsch Silkospray) on stainless steel discs. The grains were placed in the center of the aliquot which covered an area of $2-3 \mathrm{~mm}$ in diameter containing $\sim 400$ grains on average.

The preparation of the fine grained samples was done according to Frechen et al. (1996). This method includes removal of carbonates, organic material and destruction of aggregates using similar method as discussed for coarse grain sand. Separation of the 4-11 $\mu \mathrm{m}$ fraction was done by settling (based on Stokes law) using a centrifuge. The prepared polymineral fine grain material was mounted on aluminum discs by settling in acetone. Each aliquot contained $2 \mathrm{mg}$ of sample material covering the complete disc.

Coarse grained quartz from fluvial deposits and polymineral fine grain samples from flood plain deposits have been dated. Samples have been measured in the Luminescence Dating Laboratory in the Department of Geosciences at the National Taiwan University in Taipei (Taiwan, R.O.C.). Two TL/OSL systems TL-DA-15 from Risø have been used for equivalent dose estimation. Optical stimulation of quartz samples was performed using blue LEDs with a wavelength of $470 \mathrm{~nm}$ and a power of $\sim 45 \mathrm{~mW} / \mathrm{cm}^{2}$. A $7.5 \mathrm{~mm}$ thick Hoya U-340 filter was used to filter the luminescence signal from quartz. The polymineral fine grain samples were stimulated using infra-red LEDs with a wavelength of $875 \mathrm{~nm}$ and a maximum power of 400 $\mathrm{mW} / \mathrm{cm}^{2}$. A combination of Schott BG 59 and Corning 759 filter was used to filter the luminescence signal from feldspar. Signals were detected with a bialkali EMI 9235QA photomultiplier tube. Irradiation of the samples was done using a ${ }^{90} \mathrm{Sr} r{ }^{90} \mathrm{Y} \beta$-source with a dose rate of 0.25 $\mathrm{Gy} / \mathrm{s}$ and $0.08 \mathrm{~Gy} / \mathrm{s}$, respectively. According to studies from Mauz and Lang (2004) and Mauz et al. (2006), the dose rate has to be reduced for calculation of the equivalent dose obtained from fine grained samples. Our experiments showed that the dose rate for our reader using fine grains on aluminum discs is $16 \%$ lower than for coarse grain quartz on stainless steel discs.

Quartz samples were measured using the single aliquot regenerative dose (SAR) protocol based on Murray and Wintle (2000) and Wintle and Murray (2006). The aliquots were checked for contamination with feldspar using the IR-depletion ratio from Duller (2003). The feldspar in the polymineral fine grain samples was measured using a SAR protocol based on Wallinga et al.
(2007) and Murray et al. (2009). Measurements of fading rates and age correction for the feldspar samples were done using the methods from Auclair et al. (2003) and Huntley and Lamothe (2001). Prior to $\mathrm{D}_{\mathrm{E}}$ measurement, samples were subjected to a thermal transfer test and preheat-combined dose recovery test to find the suitable preheat temperature. For each sample a dose recovery test was carried out to see if the laboratory dose could be recovered with the SAR protocol.

An early background was subtracted from the initial part of the quartz OSL signal following Cunningham and Wallinga (2010). This has the advantage that the OSL signal is more dominated by the fast component. For the initial signal we took the first $0.5 \mathrm{~s}$ of stimulation and for the background, the $1.25 \mathrm{~s}$ following the initial signal. The signal from feldspar was derived from the first $10 \mathrm{~s}$ of stimulation minus a background from the last $50 \mathrm{~s}$ of stimulation.

The appropriate parameters of the SAR protocol were obtained by preheat and thermal transfer tests on selected samples as the sediment in the study area has the same source. The preheat plateau test shows if there is any temperature dependent transfer of charge which could cause erroneous $D_{E}$ determination (Wintle and Murray, 2006). Since the investigated samples are young and very likely poorly bleached we expect a scattered $\mathrm{D}_{\mathrm{E}}$ distribution, and obtaining the right preheat plateau would be difficult. Hence, we used a combination of preheat and dose recovery in our study. For this test the aliquots were bleached in the OSL reader using blue LEDs two times for $40 \mathrm{~s}$ to reset the natural signal. The bleached aliquots were then irradiated with a fixed $\beta$-dose of 2.5 Gy and measured with a SAR protocol with preheat and same cutheat temperatures ranging from $160^{\circ} \mathrm{C}$ to $300^{\circ} \mathrm{C}$ in intervals of $20^{\circ} \mathrm{C}$. For each temperature step three aliquots were measured and the mean and standard deviation were calculated. Fig. 5a shows the result of the preheat test for sample WEH2-4. For preheat temperatures from $160^{\circ} \mathrm{C}$ to $220^{\circ} \mathrm{C}$ the ratio between given and measured dose is close to unity and the scatter between the aliquots is low. For preheat temperatures from $240^{\circ} \mathrm{C}$ to $300^{\circ} \mathrm{C}$, the ratio between given and measured dose increases as does the scatter between the aliquots. Also the recycling ratios for preheat temperatures higher than $240^{\circ} \mathrm{C}$ are beyond of $10 \%$ uncertainty. The recuperation also increases strongly to mean values of $20 \%$ and $40 \%$ for preheat temperatures higher than $260^{\circ} \mathrm{C}$.

Young quartz samples can be affected by thermal transfer (Madsen et al., 2005; Wintle and Murray, 2006). A procedure similar to the preheat-dose recovery test was used to estimate thermal transfer at various temperatures without giving any artificial irradiation after bleaching the natural signal. The results of the thermal transfer test (Fig. 5b) have shown, that for preheat temperatures from $160^{\circ} \mathrm{C}$ to $220^{\circ} \mathrm{C}$ there is no significant luminescence signal due to thermal transfer. For preheat temperatures from $240^{\circ} \mathrm{C}$ to $300^{\circ} \mathrm{C}$ the equivalent dose is increasing 
from around 0.2 Gy to a maximum value of $2.1 \mathrm{~Gy}$. Based on the results of these tests a preheat and cut-heat temperature of $200^{\circ} \mathrm{C}$ was chosen for all quartz samples.

For the polymineral fine grain samples a low preheat and cut-heat temperature of $160^{\circ} \mathrm{C}$ was taken. The results of the thermal transfer test showed a strong increase of the equivalent dose for preheat temperatures higher than $200^{\circ} \mathrm{C}$ from around 0.2 Gy to a maximum value of 6.9 Gy (Fig. 5b).

Dose recovery tests have been performed for all samples to test whether a laboratory dose can be recovered by the applied SAR protocol. For each sample 10 aliquots were measured. The aliquots were bleached in the OSL reader by blue LEDs or infrared LEDs to remove the natural signal. After bleaching the samples were given a fixed $\beta$-dose which was close to the expected equivalent dose and was measured using the selected SAR protocol. For an optimum SAR protocol the ratio of the recovered dose to the applied dose should be in the range of $1.0 \pm 0.1$ (Murray and Wintle, 2003). The results of the dose recovery tests are summarized in Table 1 . Based on the results of the tests a SAR protocol was developed (Table 2) and the equivalent doses were determined using this protocol.

(a)

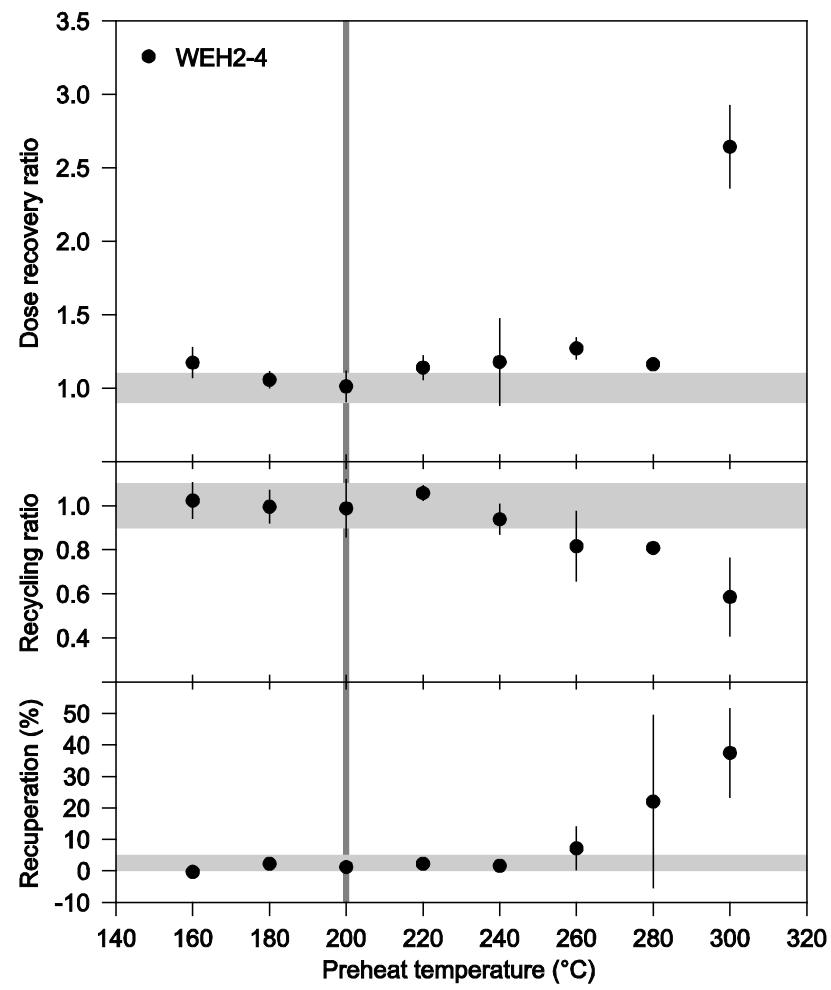

\section{Dose rate estimation}

The natural luminescence signal is the result of the interaction of radiation from the surrounding sediment with the crystal structure. Radiation in the sediment derives from the natural radioactivity mainly from the decay of $\mathrm{U}, \mathrm{Th}, \mathrm{K}$, and their daughters. It is essential for the calculation of the age to know the dose rate of the sediment. Dose rate estimation was done by gamma-ray spectrometry in the Section S3: Geochronology and Isotope Hydrology at the Leibniz Institute for Applied Geophysics in Hannover (Germany). Untreated samples were dried, homogenized and filled into Marinelli beakers which had been sealed to avoid exchange of $\mathrm{Rn}$ and were stored for at least 4 weeks to attain equilibrium. An N-type coaxial HPGe detector was used for measurement. Energy and efficiency of the detector were calibrated using reference material from the International Atomic Energy Agency: IAEA-RGK-1, IAEA-RGU-1 and IAEA-RGTh-1. Measurements were performed for $700 \mathrm{~g}$ samples in Marinelli beakers for at least 24 hours or until the ${ }^{40} \mathrm{~K}$ peak reached 1,000 counts. Uranium series activity was calculated from the activities of the daughter nuclides ${ }^{234} \mathrm{Th},{ }^{214} \mathrm{~Pb}$ and ${ }^{214} \mathrm{Bi}$. Thorium series activity was calculated from the activities of the daughter nuclides ${ }^{228} \mathrm{Ac},{ }^{212} \mathrm{~Pb}$ and ${ }^{208} \mathrm{Tl}$. (b)

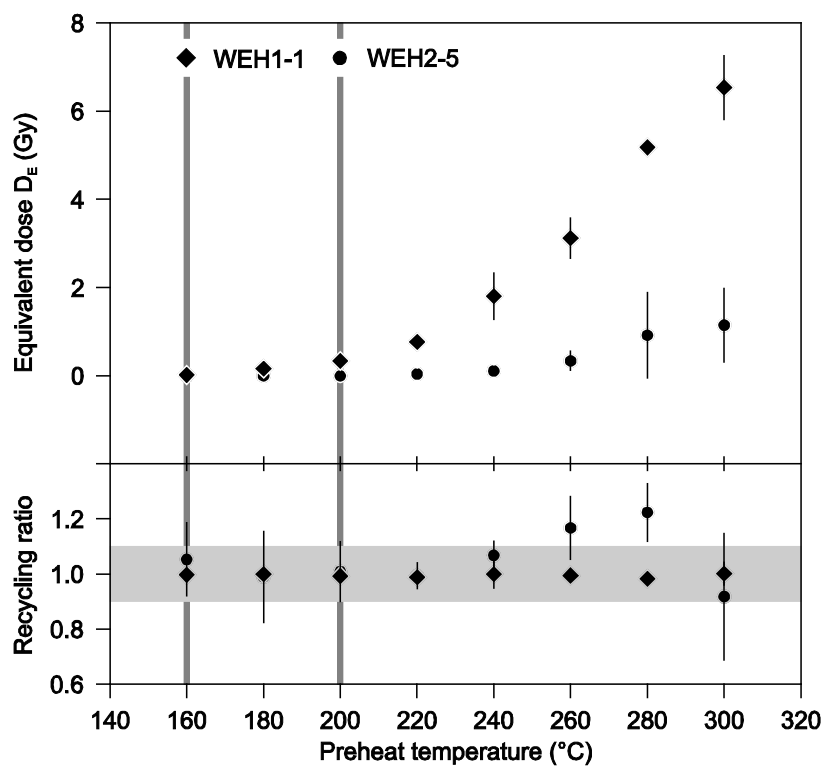

Fig. 5. (a): Results of preheat and dose recovery test for sample WEH2-4. Grey horizontal bars indicate range of acceptance for dose recovery ratio and recycling ratio of $1.0 \pm 0.1$ and for the recuperation of $0 \%$ to $5 \%$. (b): Results of the thermal transfer test for samples WEH1-1 and WEH2-5. Grey horizontal bar indicates range of acceptance of $1.0 \pm 0.1$ for the recycling ratio. In both figures for each temperature the mean value from three aliquots and the standard deviation is shown. Chosen preheat temperature is highlighted by dark grey vertical lines. For a detailed description see text. 
The activity of ${ }^{40} \mathrm{~K}$ was measured directly. The cosmic radiation contributes to the dose rate in the sediment and depends on latitude, altitude and depth of deposition. In this study the approach from Prescott and Stephan (1982) and Prescott and Hutton (1994) was used to calculate the cosmic dose rate. As samples were taken from very thin layers or close to adjacent layers the dose rates were corrected by calculating the dose rates from the activity concentration at the sampling depth and from adjacent layers (Aitken, 1985). The annual dose rate was corrected for attenuation by water in the sediment using the percentage of present day moisture content to the dry weight of the sample. As the investigated sections are periodically flooded and ground water level can change, the error for the water content was set large to take these seasonal fluctuations into account. Details of moisture content used and dose rate calculation are summarized in Table 3.

Table 1. Results of the dose recovery test. For each sample 10 aliquots were measured. Dose recovery ratio is the ratio between applied dose and recovered dose.

\begin{tabular}{|c|c|c|c|c|c|c|c|}
\hline Sample & $\begin{array}{c}\text { Applied Dose } \\
(G y)\end{array}$ & $\begin{array}{c}\text { Recovered Dose } \\
(\mathrm{Gy})^{*}\end{array}$ & $\begin{array}{l}\text { Relative Standard } \\
\text { Deviation }(\%)^{\dagger}\end{array}$ & $\begin{array}{l}\text { Accepted } \\
\text { Aliquots }\end{array}$ & $\begin{array}{c}\text { Dose Recovery } \\
\text { Ratio }\end{array}$ & Recycling Ratio & Recuperation \\
\hline WEH1-1 & 4.025 & $4.164 \pm 0.073$ & 1.75 & 10 & $1.04 \pm 0.02$ & $0.98 \pm 0.02$ & $<6 \%$ \\
\hline WEH1-2 & 2.473 & $2.744 \pm 0.415$ & 15.12 & 8 & $1.03 \pm 0.03$ & $0.91 \pm 0.09$ & $<4 \%$ \\
\hline WEH2-1 & 3.945 & $3.946 \pm 0.058$ & 1.46 & 10 & $1.00 \pm 0.01$ & $0.98 \pm 0.02$ & $<6 \%$ \\
\hline WEH2-2 & 2.473 & $2.474 \pm 0.182$ & 7.36 & 8 & $1.01 \pm 0.06$ & $0.96 \pm 0.08$ & $<3 \%$ \\
\hline WEH2-3 & 3.945 & $3.941 \pm 0.060$ & 1.52 & 10 & $0.99 \pm 0.02$ & $0.98 \pm 0.02$ & $<6 \%$ \\
\hline WEH2-4 & 2.473 & $2.564 \pm 0.104$ & 4.06 & 10 & $1.04 \pm 0.04$ & $0.97 \pm 0.10$ & $<2 \%$ \\
\hline WEH2-5 & 2.473 & $2.514 \pm 0.375$ & 14.90 & 9 & $0.97 \pm 0.06$ & $1.02 \pm 0.08$ & $<3 \%$ \\
\hline
\end{tabular}

${ }^{*}$ Mean and standard deviation from all aliquots.

+ Relative standard deviation from the mean of the recovered doses. This value is used as threshold in the method after Fuchs and Lang (2001).

Table 2. SAR-protocols used to measure the equivalent dose of coarse grain quartz and polymineral fine grain samples from Wehningen. For the natural sample $i=0$ and $D_{0}=0$. The whole sequence is repeated for several regenerative doses, including a zero dose and a repeat dose. The ratio between $L_{i} / T_{i}$ is used to construct the growth curve from which the equivalent dose is obtained.

\begin{tabular}{llll}
\hline Step & Treatment & coarse grain quartz & fine grain feldspar \\
\hline 1 & Give regenerative dose $D_{i}$ & $1.25 \mathrm{~Gy}$ to $7.5 \mathrm{~Gy}$ & $2.4 \mathrm{~Gy}$ to $8 \mathrm{~Gy}$ \\
2 & Preheat $\left(5^{\circ} \mathrm{C} / \mathrm{s}\right.$ heating rate $)$ & $200^{\circ} \mathrm{C}$ for $10 \mathrm{~s}$ & $160^{\circ} \mathrm{C}$ for $60 \mathrm{~s}$ \\
3 & Stimulation with light and measurement of signal $L_{i}$ & blue LED for $40 \mathrm{~s}$ at $125^{\circ} \mathrm{C}$ & IR-LED for $300 \mathrm{~s}$ at $50^{\circ} \mathrm{C}$ \\
4 & Give test dose $D_{T}$ & $1.25 \mathrm{~Gy}$ & $2.4 \mathrm{~Gy}$ \\
5 & Cut-heat $\left(5^{\circ} \mathrm{C} / \mathrm{s}\right.$ heating rate) & $200^{\circ} \mathrm{C}$ for $0 \mathrm{~s}$ & $160^{\circ} \mathrm{C}$ for $60 \mathrm{~s}$ \\
6 & Stimulation with light and measurement of signal $T_{i}$ & blue LED for $40 \mathrm{~s}$ at $125^{\circ} \mathrm{C}$ & IR-LED for $300 \mathrm{~s}$ at $50^{\circ} \mathrm{C}$ \\
\hline
\end{tabular}

Table 3. Results of gamma-ray spectrometry and dose rate calculation. Dose rate at sampling position is the sum of dose rates from alpha, beta, gamma and cosmic radiation attenuated by the water content. Samples were taken close to neighbouring layers hence correction of the dose rate for contribution from surrounding layers was necessary. This was done according to Aitken (1985) and the corrected dose rate was then used for age calculation. For calculation of the dose rates conversion factors published by Guerin et al. (2011) were used. A systematic error of $8 \%$ is included for the calculation of the dose rates including uncertainties from beta-attenuation, conversion factors, calibration of the gamma-ray detector and effects of past disequilibrium (Murray and Olley, 2002; Olley et al., 1996). An error of $10 \%$ is estimated for the cosmic dose. For the polymineral fine grain samples an a-value of 0.08 \pm 0.01 for the alpha-efficiency was used (Rees-Jones and Tite, 1997). Due to the etching of the outer rim of the quartz grains, contribution by alpha particles is negligible and hence an a-value of zero was used.

\begin{tabular}{|c|c|c|c|c|c|c|c|c|c|c|}
\hline Sample ID & $\begin{array}{l}\text { Height } \\
\text { (m a.s.l.) }\end{array}$ & $\begin{array}{l}\text { Depth } \\
(\mathrm{m})\end{array}$ & $\begin{array}{l}\text { Grain } \\
\text { Size } \\
(\mu \mathrm{m})\end{array}$ & $\begin{array}{l}\mathrm{H}_{2} \mathrm{O} \\
(\%)\end{array}$ & $\begin{array}{c}238 \mathrm{U} \\
(\mathrm{ppm})\end{array}$ & $\begin{array}{l}\text { 232Th } \\
\text { (ppm) }\end{array}$ & $\begin{array}{c}\mathrm{K} \\
(\%)\end{array}$ & $\begin{array}{l}\text { Cosmic Dose } \\
\text { (mGy/a) }\end{array}$ & $\begin{array}{l}\text { Dose Rate at } \\
\text { Sampling } \\
\text { Position } \\
\text { (mGyla) }\end{array}$ & $\begin{array}{c}\text { Corrected } \\
\text { Dose } \\
\text { Rate } \\
\text { (mGyla) }\end{array}$ \\
\hline WEH1-1 & 13.7 & 0.40 & $4-11$ & $21 \pm 10$ & $3.08 \pm 0.15$ & $10.32 \pm 0.52$ & $1.82 \pm 0.09$ & $0.21 \pm 0.02$ & $3.31 \pm 0.23$ & $3.29 \pm 0.23$ \\
\hline WEH1-2 & 13.7 & 1.10 & $150-250$ & $6 \pm 3$ & $0.69 \pm 0.03$ & $2.32 \pm 0.12$ & $0.88 \pm 0.04$ & $0.19 \pm 0.02$ & $1.07 \pm 0.12$ & $1.11 \pm 0.12$ \\
\hline WEH2-1 & 12.9 & 0.55 & 4-11 & $20 \pm 10$ & $4.70 \pm 0.24$ & $10.72 \pm 0.54$ & $1.62 \pm 0.08$ & $0.20 \pm 0.02$ & $3.69 \pm 0.26$ & $3.67 \pm 0.23$ \\
\hline WEH2-2 & 12.9 & 0.67 & $100-200$ & $6 \pm 3$ & $0.61 \pm 0.03$ & $1.94 \pm 0.10$ & $0.90 \pm 0.05$ & $0.20 \pm 0.02$ & $1.07 \pm 0.12$ & $2.44 \pm 0.12$ \\
\hline WEH2-3 & 12.9 & 0.78 & 4-11 & $24 \pm 12$ & $3.48 \pm 0.17$ & $10.23 \pm 0.51$ & $1.82 \pm 0.09$ & $0.19 \pm 0.02$ & $3.32 \pm 0.24$ & $3.84 \pm 0.21$ \\
\hline WEH2-4 & 12.9 & 0.90 & $100-200$ & $6 \pm 3$ & $0.61 \pm 0.03$ & $1.94 \pm 0.10$ & $0.90 \pm 0.05$ & $0.19 \pm 0.02$ & $1.07 \pm 0.12$ & $2.52 \pm 0.12$ \\
\hline WEH2-5 & 12.9 & 1.20 & $150-250$ & $5 \pm 2$ & $0.53 \pm 0.03$ & $1.56 \pm 0.08$ & $0.91 \pm 0.05$ & $0.18 \pm 0.02$ & $1.04 \pm 0.12$ & $1.17 \pm 0.11$ \\
\hline
\end{tabular}




\section{DATA ANALYSIS}

\section{Preparation of the data set}

For each coarse grained quartz sample, 96 aliquots were measured to get sufficient number of equivalent doses for statistical analysis. For polymineral fine grain samples, 40 aliquots were measured. The growth curves of the quartz samples were fitted using a linear function and for the polymineral fine grain samples, a single exponential rise to maximum function was used. The error of each equivalent dose includes counting statistic, error in curve fitting and $2 \%$ measurement error. $D_{E}$ values were accepted for final $D_{\mathrm{E}}$ estimate, only when the recycling ratio obtained within $15 \%$ uncertainty, the IRdepletion ratio is between 1.0 and 0.8 , indicating no feldspar contamination and the recuperation is not exceeding $5 \%$ of the natural signal. The number of accepted aliquots is shown in Table 4. It can be seen that for samples WEH1-2 and WEH2-5 from the basal sand layers, 70\% of the measured aliquots passed whereas for samples WEH2-2 and WEH 2-4 from the sand layers, almost 90\% passed. Most of the rejected aliquots had shown poor signal to noise ratio and lower sensitivity. In Fig. 6 examples of OSL signal decay curves and growth curves for sample WEH2-5 are shown. All aliquots from the polymineral fine grain samples showed bright signals and good growth curves as demonstrated in Fig. 6. All aliquots from the polymineral fine grain samples passed the acceptance criteria and were used for $\mathrm{D}_{\mathrm{E}}$ estimation. Our data sets were not checked for outliers. Tests for outliers are based on the assumption that the data has a normal distribution, which is not the case for the fluvial samples here. Applying outlier tests would truncate the data sets. The $\mathrm{D}_{\mathrm{E}}$ distributions of the polymineral fine grain samples show clearly the absence of outliers so no statistical test was applied.

To characterize the distribution for each sample, statistical parameters were calculated (Table 4). These are overdispersion $\left(\sigma_{O D}\right)$ using the central age model from Galbraith et al. (1999) and the overdispersion $\left(\sigma_{O D(U L)}\right)$ from the unlogged central age model (Galbraith and Roberts, 2012), skewness and kurtosis with their standard error using the formulas presented in Bailey and Arnold (2006). We also used the Kolmogorov-Smirnov-test to see if the distribution of equivalent doses follows a normal distribution. The $\mathrm{D}_{\mathrm{E}}$ distributions for all coarse grain quartz samples are shown in Fig. 7 and for all polymineral fine grain samples in Fig. 8. For each sample we included a scatter plot showing the errors against the $\mathrm{D}_{\mathrm{E}}$ values on a linear scale, a kernel density estimate (KDE) which is an estimate of the probability density function and a radial plot which is an ideal plot to show variations in $\mathrm{D}_{\mathrm{E}}$ values and their different precisions. Details and advantages of these forms of graphical displays are highlighted in Galbraith and Roberts (2012). Radial plots and kernel density estimate plots were generated using Radial Plotter 1.3 from Vermeesch (2009).

\section{Age models and paleodose calculation}

In completely bleached sediments, the distribution of the equivalent doses of a sample should be close to the arithmetic mean. In heterogeneously bleached samples, such as fluvial sediments, the $D_{\mathrm{E}}$ distribution generally shows larger variability. Several authors (e.g. Duller, 1994; Murray et al., 1995; Olley et al., 1998; Lepper and McKeever, 2002; Geyh, 2008) described a strong positively-shifted distribution in younger sediments. In such cases it is hard to decide which of the equivalent doses represents the 'true' depositional age. Different techniques were worked out to exclude insufficiently bleached signal components from the paleodose $\left(D_{P}\right)$ estimation and statistical test can in many cases improve the degree of confidence in the results. In this study we calculated the paleodose $\left(D_{P}\right)$ from equivalent dose $\left(D_{E}\right)$ distribution using the following methods such as mean and median, method after Fuchs and Lang (2001), leading edge model from Lepper and McKeever (2002), central age model and minimum age model after Galbraith et al. (1999) and their unlogged counterparts based on Arnold et al. (2009). For completeness we also mention the approaches from Murray et al. (1995), Olley et al. (1998) and Cunningham and Wallinga (2012). These models were not used in this study and the reasons are described in the following sections.

Table 4. Statistic parameters of the investigated samples. Aliquots shows the number of accepted aliquots which have been used for data analysis. Total number of measured aliquots is shown in parenthesis. Overdispersion $(\sigma 0 D)$ was calculated using the central age model from Galbraith et al. (1999) and $\sigma_{O D}(U L)$ was calculated from the unlogged central age model following Galbraith and Roberts (2012). Skewness and kurtosis are shown with their standard error, which was calculated using the formulas presented in Bailey and Arnold (2006). The K-S-test values are obtained using the Kolmogorov-Smirnov-Test. If the K-S-test value is lower than the critical K-S-test value then the distribution of the data is normal.

\begin{tabular}{lccccccc}
\hline Sample & Aliquots & $\sigma o D(\%)$ & $\sigma 0 D(\mathrm{UL})(\%)$ & Skewness & Kurtosis & K-S-Test Value & Critical K-S-Test Value \\
\hline WEH1-1 & $40(40)$ & $3 \pm 1$ & $2 \pm 1$ & $0.46 \pm 0.39$ & $-0.31 \pm 0.77$ & 0.071 & 0.196 \\
WEH1-2 & $67(96)$ & $115 \pm 10$ & $162 \pm 36$ & $2.87 \pm 0.30$ & $8.15 \pm 0.60$ & 0.366 & 0.166 \\
WEH2-1 & $40(40)$ & $5 \pm 1$ & $4 \pm 1$ & $0.60 \pm 0.39$ & $1.16 \pm 0.77$ & 0.121 & 0.196 \\
WEH2-2 & $85(96)$ & $37 \pm 4$ & $42 \pm 4$ & $2.79 \pm 0.27$ & $8.85 \pm 0.53$ & 0.224 & 0.148 \\
WEH2-3 & $40(40)$ & $4 \pm 1$ & $4 \pm 1$ & $-0.01 \pm 0.39$ & $-0.07 \pm 0.77$ & 0.071 & 0.196 \\
WEH2-4 & $85(96)$ & $64 \pm 5$ & $135 \pm 22$ & $7.90 \pm 0.27$ & $67.68 \pm 0.53$ & 0.372 & 0.148 \\
WEH2-5 & $66(96)$ & $50 \pm 6$ & $129 \pm 24$ & $6.84 \pm 0.30$ & $51.28 \pm 0.60$ & 0.382 & 0.167 \\
\hline
\end{tabular}


(a)

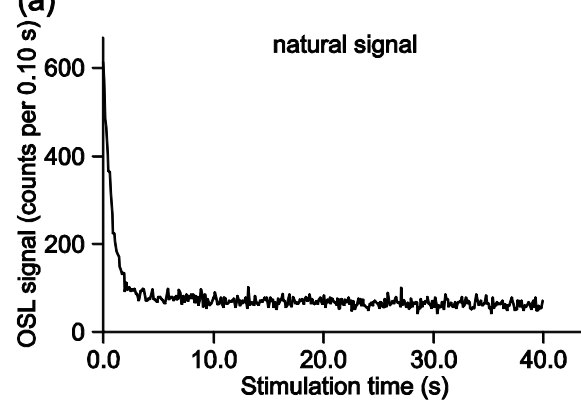

(d)

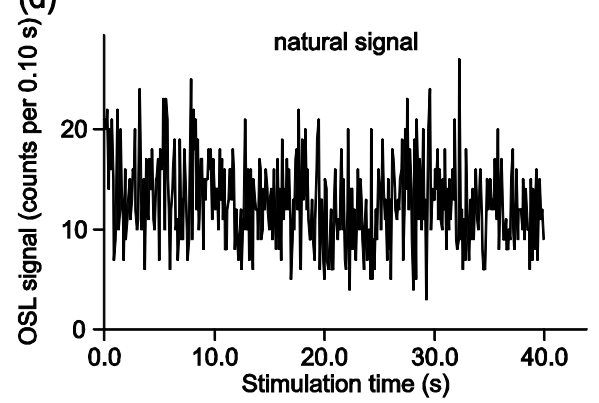

(g)

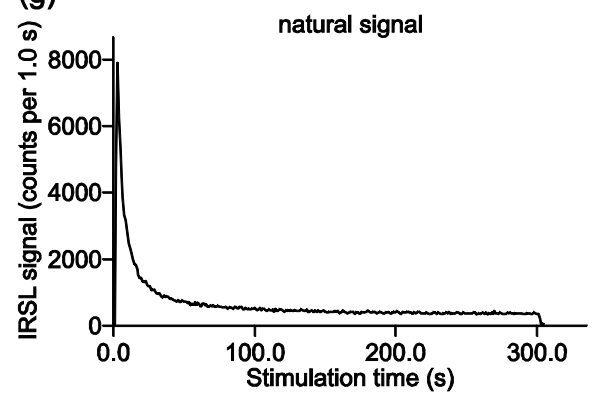

(b)

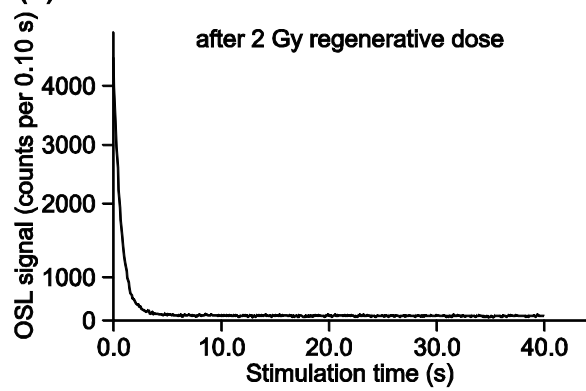

(e)

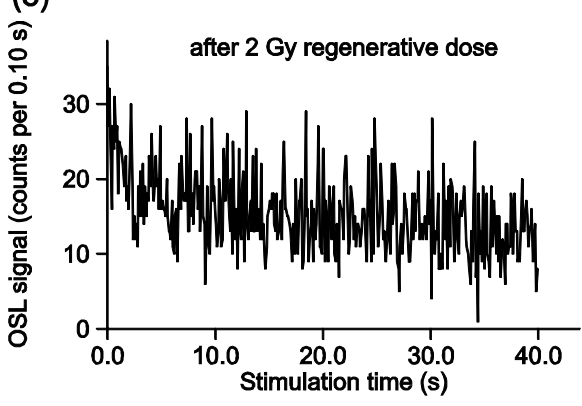

(h)

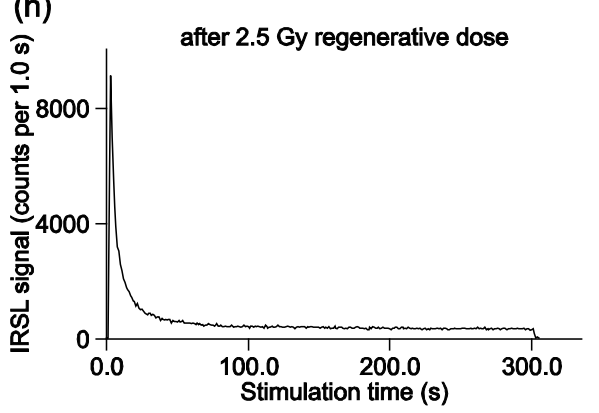

(c)

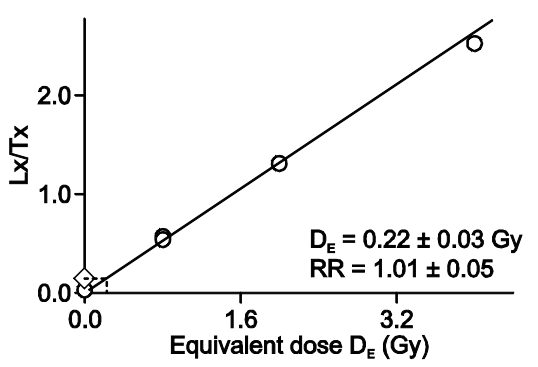

(f)

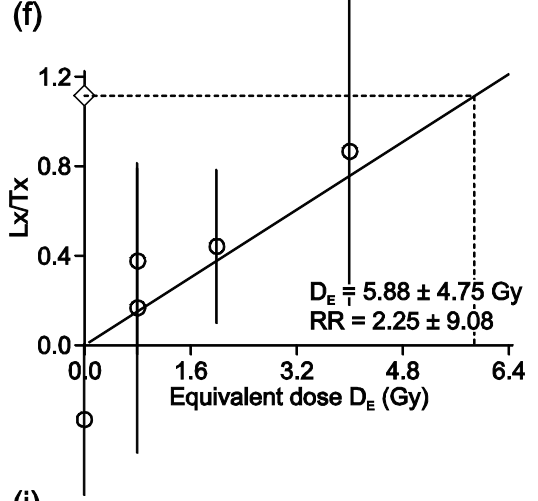

(i)

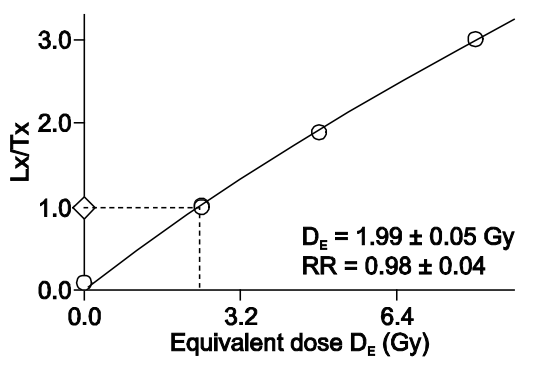

Fig. 6. Examples of OSL signals and growth curves for coarse grain quartz sample WEH2-5 (a) to (f) and polymineral fine grain sample WEH1-1 (g) to (i). Diamond in growth curves (c), (f), (i) represents the $L_{n} / T_{n}$ of the natural signal. Circles are showing the $L_{x} T_{x}$ values for the regenerative doses. Some error bars are too small to be seen in the figure. The uppermost two rows are showing the natural OSL signals (a), (d), the OSL signals after beta-irradiation with $2 \mathrm{~Gy}(b),(e)$, and the resulting growth curves (c), (f), for different aliquots from sample WEH2-5. In the row (d) to (f) one aliquot with not acceptable OSL behavior is shown. There was no natural OSL signal (d) detectable and after beta-irradiation with 2 Gy the OSL signal was still low (e). These low OSL signals are leading to $L_{x} T_{x}$ values with large errors and unreliable equivalent dose estimation for this aliquot. All aliquots from the polymineral fine grain samples showed signals and growth curves as represented by the aliquot shown in the row (g) to (i). $R R=$ recycling ratio.

\section{Method after Fuchs and Lang (2001)}

This method was developed for samples having less proportion of heterogeneously bleached grains. Dose recovery tests are used to characterize the precision and accuracy of the SAR procedure. It is assumed that the scatter of the $D_{E}$ values obtained from dose recovery tests represents the best achievable precision for natural samples, whereas larger scatter is the result of incomplete bleaching of grains before deposition. For each sample, dose recovery tests have to be made and from all recovered dose, the arithmetic mean and relative standard deviation is calculated. This value is used as threshold for calculation of the paleodose $D_{P}$ from the set of $D_{E} o b$ tained by the SAR measurement. Practically, this is done by calculating the arithmetic mean starting from the two lowermost $\mathrm{D}_{\mathrm{E}}$ and stepwise increasing the number of $\mathrm{D}_{\mathrm{E}}$ creating a running mean. This procedure stops when the relative standard deviation reaches the same value as the relative standard deviation of the dose recovery test. This mean is used for age calculation. In this study, dose recovery tests as described in the previous section were made for all samples using 10 aliquots. The relative standard deviation from the arithmetic mean of the obtained doses was calculated (Table 1) and used as the threshold for calculation of the burial dose here. The error is the standard deviation. 

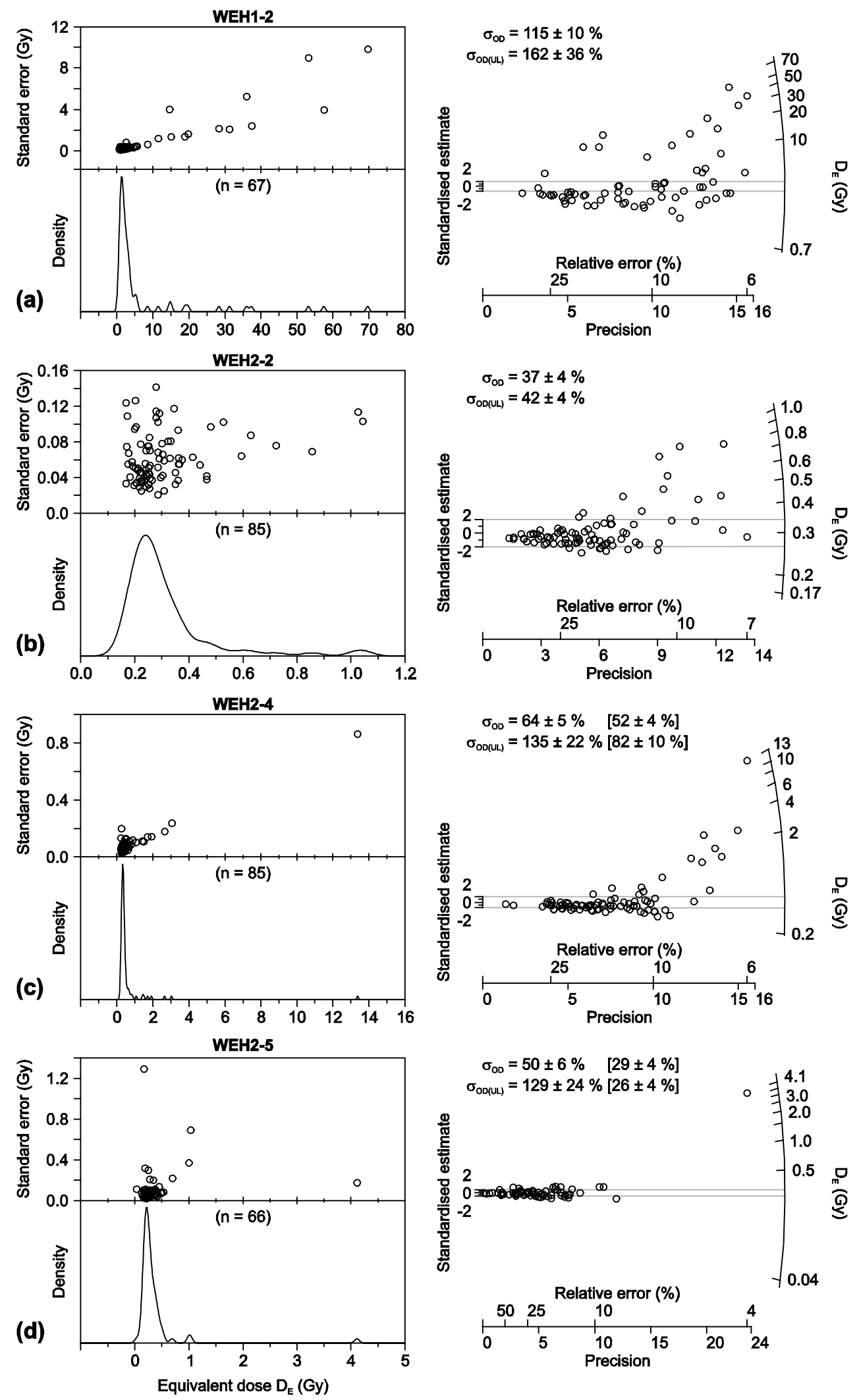

Fig. 7. Equivalent dose $\left(D_{E}\right)$ distributions of the coarse grained quartz samples. For each sample a graph of standard error versus $D_{E}$ estimate, kernel density estimate (both on unlogged $D_{E}$ scale) and a radial plot (on a log $D_{E}$ scale) is shown. The overdispersion value calculated from the central age model is given as $\sigma_{O D}$ and from the unlogged central age model as $\sigma_{O D}(U L)$. Overdispersion values displayed in squared brackets are calculated without the highest $D_{E}$ value from the distribution. 

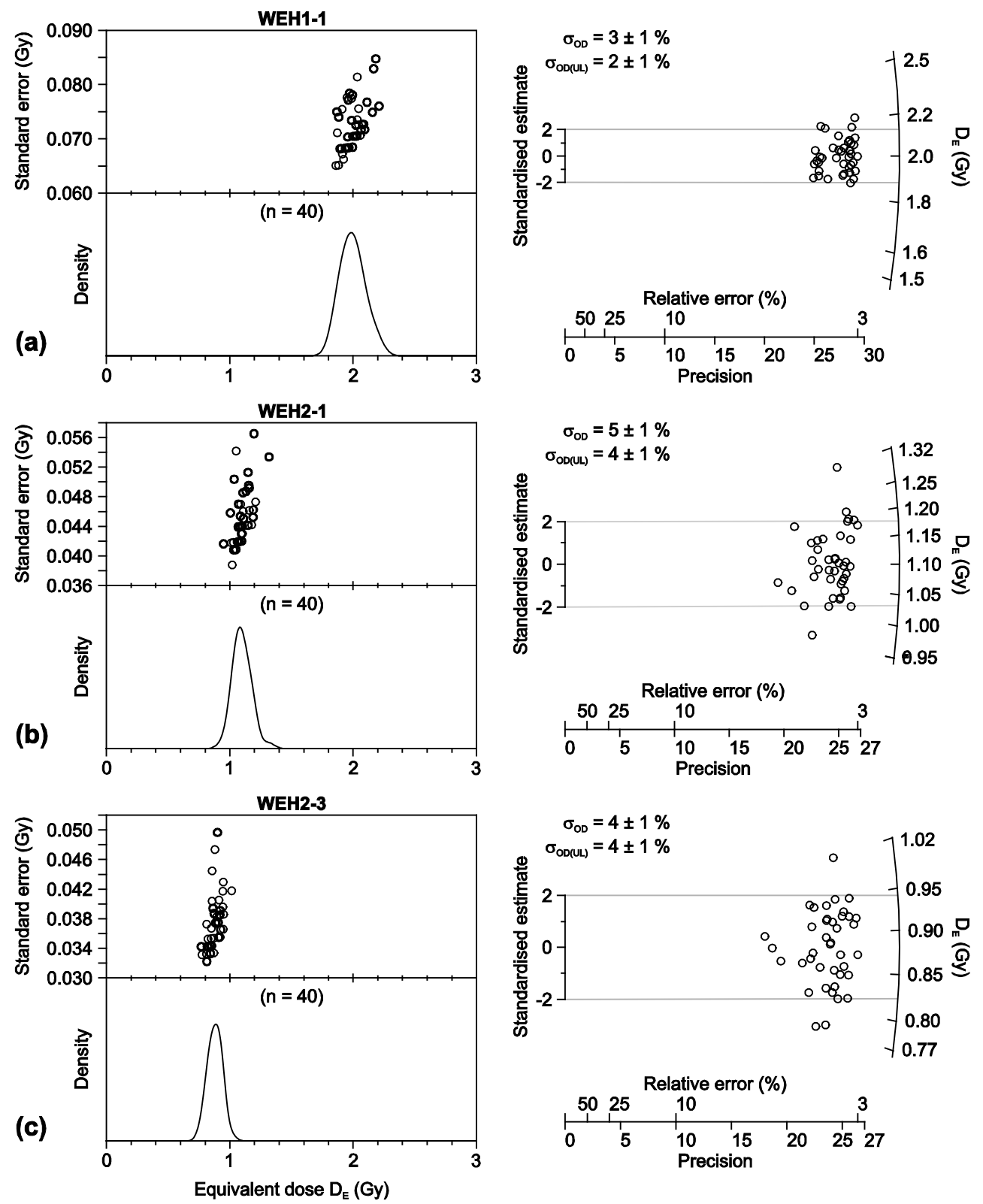

Fig. 8. Equivalent dose $\left(D_{E}\right)$ distributions of the polymineral fine grain samples. For each sample a graph of standard error versus $D_{E}$ estimate, kernel density estimate (both on unlogged $D_{E}$ scale) and a radial plot (on a $\log D_{E}$ scale) is shown. The overdispersion value calculated from the central age model is given as $\sigma 00$ and from the unlogged central age model as $\sigma O D$ (UL).

\section{Leading edge model from Lepper and McKeever (2002)}

This model is based on the assumption that on the rising limb (leading edge) of a dose distribution an edge effect occurs. In well bleached sediments, as in loess or fine grained dune sands, the luminescence signal of nearly all grains should be set to zero at deposition which is expressed in a narrow $\mathrm{D}_{\mathrm{E}}$ distribution. On the other hand, young fluvial sediments tend to show a broader $\mathrm{D}_{\mathrm{E}}$ distribution due to different amount of bleaching and re-setting of the luminescence signal before deposition. As the reset of the grains can never be less than zero, an edge effect in the $\mathrm{D}_{\mathrm{E}}$ distribution can still exist. This leading edge is associated with grains that were completely reset before deposition, therefore the leading edge equivalent dose should represent the age of deposition best. The paleodose $D_{P}$ is calculated from the second derivative of the Gaussian equation which is fitted to the rising limb of a histogram of the $\mathrm{D}_{\mathrm{E}}$ distribution. This method has the advantage of being straightforward and easy to apply, but it suffers from the issue of the appropriate bin width for the histogram. With this step, subjectivity can enter into the analysis as bin widths for histograms are an arbitrary choice. If the bin width is too small, the resolution of the histogram will be too high and no clear rising limb is 
recognizable. This hampers proper fitting of the Gaussian equation and can lead to age underestimation as only a few lowest $D_{E}$ values are taken into account. On the other hand, a bin width which is too large will reduce the resolution of the histogram and fitting to the rising limb may result in higher ages. Lepper and McKeever (2002) suggest as an objective bin width the median of the errors from the equivalent doses. For our samples we used the same method to obtain the bin width for each dose histogram which was then used to calculate the paleodose. The error for the paleodose is calculated using the formula presented in Lepper and McKeever (2002).

\section{Central age and minimum age models}

These models have been originally developed for fission track analysis (Galbraith and Laslett, 1993; Galbraith and Green, 1990) and later adapted to OSL dating (Galbraith et al., 1999). The central age model (CAM) was developed to be used for distributions of equivalent doses that are not consistent with a common value. The central age model is based on the assumption that the true $\log$ paleodoses $\delta_{\mathrm{i}}$ are a random sample from a normal distribution with the mean $\delta$ and standard deviation $\sigma$ (Galbraith et al. 1999). When $\sigma$ is zero the central age model becomes equivalent to the common age model (similar to weighted average) (Galbraith et al. 1999). The central log paleodose $\delta$ is interpreted as the mean of the true $\log$ paleodose $\delta_{\mathrm{i}}$ and is calculated from a weighted average. For the minimum age model (MAM) it is assumed that the distribution of the equivalent doses for partially bleached grains has a truncated normal distribution. The lower truncation point represents the average $D_{E}$ of the fully bleached grains. Due to the use of log-transformed datasets the CAM and MAM is difficult to apply for young or modern samples with near-zero or zero $\mathrm{D}_{\mathrm{E}}$ values. Therefore un-logged versions of the CAM $\left(\mathrm{CAM}_{\mathrm{UL}}\right)$ and MAM $\left(\mathrm{MAM}_{\mathrm{UL}}\right)$ have been developed by Arnold et al. (2009). In this study we used the CAM and MAM-3 and the un-logged counterparts $\mathrm{CAM}_{\mathrm{UL}}$ and MAM- $3_{\mathrm{UL}}$ to calculate the 'true' paleodose for our samples. Calculations of the MAM-3 and MAM-3 $3_{U L}$ were done using scripts for MATLAB provided by the Netherlands Centre for Luminescence Dating, whereas the CAM and $\mathrm{CAM}_{\mathrm{UL}}$ were calculated using Excel spreadsheets.

\section{Age models from Murray et al. (1995), Olley et al. (1998) and Cunningham and Wallinga (2012)}

In the work from Murray et al. (1995) young fluvial sediments from Australia with independent age control have been investigated. Murray et al. (1995) suggested calculating the equivalent doses from the arithmetic mean of all measured aliquots excluding the three highest $\mathrm{D}_{\mathrm{E}}$ values. Technically this approach cannot be regarded as an age model as their decision to remove the three highest $\mathrm{D}_{\mathrm{E}}$ values from the distribution is too arbitrary and has no empirical basis. In the study from Olley et al. (1998) quartz grains from young fluvial sediments were dated. For this specific set of samples, independent age control was available and validation of their results was possible. Olley et al. (1998) found that 5\% of the $\mathrm{D}_{\mathrm{E}}$ values from the modern sample are consistent with zero and calculated the burial dose from the lowest $5 \%$ of $D_{E}$ values from the distribution in the fluvial samples. In practice this method has the issue that it requires calibration to knownage material assuming that it has the same luminescence characteristics as the sample of unknown age. Hence, we cannot apply this method in our study as no modern sample material of the fluvial sand is available for calibration. Recent major flood events in the years $2006 \mathrm{AD}$ and 2011 AD did not leave any sand deposits in the study area. In the approach from Cunningham and Wallinga (2012) the software OxCAL v4.1 is used to calculate the depositional age from fluvial samples. Before doing this, probability density functions (PDF) have to be created for each data set. As this is not straightforward for partially bleached samples, a method using bootstrap likelihoods is applied to obtain PDF for each data set. To use the full potential of Bayesian statistics, this method requires high resolution sampling.

From each statistical approach the paleodose $D_{\mathrm{P}}$ was calculated. The depositional age was then obtained by dividing $\mathrm{D}_{\mathrm{P}}$ by the annual dose rate which includes the corrected sediment dose rate and contribution from cosmic rays following Aitken (1998).

\section{RESULTS}

The ages obtained are in stratigraphic order and generally in agreement with the historical records, except of the polymineral fine grain samples. The results of the gamma-ray spectrometry and annual dose rate are summarized in Table 3. Higher concentration of uranium, thorium and potassium were observed in the floodplain deposits compared to the sand layers. Annual dose rates at sampling position for the sand layers are around $1 \mathrm{mGy} / \mathrm{a}$ and for the floodplain deposits it is $3.3 \mathrm{mGy} / \mathrm{a}$ and $3.6 \mathrm{mGy} / \mathrm{a}$. The corrected annual dose rates are slightly higher according to contributions of the neighboring layers.

\section{$D_{E}$ distribution of coarse grain quartz samples}

For coarse grain quartz samples, the $\mathrm{D}_{\mathrm{E}}$ values were distributed largely towards the lower end of the distribution with few values towards the higher side.

Samples WEH1-2 from section 1 and WEH2-2 from the upper sand layer in section 2 are showing a broad $\mathrm{D}_{\mathrm{E}}$ distribution with a dominant peak in the KDE plot and a tail with evenly distributed higher $\mathrm{D}_{\mathrm{E}}$ values up to $70 \mathrm{~Gy}$ (Fig. 7). A slightly different $\mathrm{D}_{\mathrm{E}}$ distribution can be seen for samples WEH2-4 from the lower sand layer in section 2 and WEH2-5 from the sand at the base in section 2. For both samples the obtained $D_{\mathrm{E}}$ values are in a narrow range (0.2-0.4 Gy for WEH2-4 and 0.1-0.5 Gy for 
WEH2-5) and only a few values with higher $\mathrm{D}_{\mathrm{E}}$ (Fig. 7). In both data sets one aliquot with higher $\mathrm{D}_{\mathrm{E}}$ value occurs. The OSL properties of these specific aliquots are very good with bright luminescence signals. It could be likely that they contain grains which were not bleached before deposition.

The lowest overdispersion values were obtained for sample WEH2-2 with $37 \pm 4 \%$ and $42 \pm 4 \%$ and the highest values for sample WEH1-2 with $115 \pm 10 \%$ and $162 \pm 36 \%$ (Table 4) calculated from the CAM and $\mathrm{CAM}_{\mathrm{UL}}$, respectively.

A positive skew of all $D_{E}$ distributions is also reflected by positive values for skewness ranging from $2.79 \pm 0.27$ (WEH2-2) to $7.90 \pm 0.27$ (WEH2-4) (Table 4). Values of the kurtosis (Table 4) are indicating leptokurtic distributions with sharp peaks for samples WEH1-2 and WEH2-2 and very sharp peaks for samples WEH2-4 and WEH2-5. The Kolmogorov-Smirnov-Test results (K-STest) show values for all samples which are two or three times higher than the critical K-S-Test values (Table 4).

\section{$D_{E}$ distribution of polymineral fine grain samples}

The $D_{E}$ distribution of the polymineral fine grain samples (WEH1-1, WEH2-1 and WEH2-3) differs significantly from the coarse grain samples. They all show a unimodal distribution with a very low scatter of $D_{E}$ values (Fig. 8). Overdispersion values $\sigma_{\mathrm{OD}}$ and $\sigma_{\mathrm{OD}(\mathrm{UL})}$ are very low and range from $2 \pm 1 \%$ to $5 \pm 1 \%$, typical for fully bleached sediments (Alappat et al. 2011; Kunz et al. 2010). In the radial plot, all samples show high precision values of around $25 \%$ and low relative errors of $3 \%$. The values for skewness are close to zero (for WEH2-3) indicating a symmetrical distribution of $\mathrm{D}_{\mathrm{E}}$ values (Table 4). Similarly, the values for the kurtosis are also close to zero indicating a shape of the distribution close to a normal distribution. This is also supported by the K-S-test values which are lower than the critical K-S-test values.

\section{Ages of coarse grain quartz samples}

The ages for the coarse grain sample WEH1-2 have shown wide variation (Table 5, Fig. 2). They range from $5330 \pm 1180$ a to $820 \pm 230$ a (All ages presented here, related to the year of sampling in $2010 \mathrm{AD}$ ). Ages calculated from the mean and the $\mathrm{CAM}_{\mathrm{UL}}$ are the highest and also show large errors with $4680 \pm 9000$ a and $5330 \pm 1180$ a, respectively. The youngest ages are calculated from the method after Fuchs and Lang (2001) and the leading edge model with $840 \pm 110$ a and $820 \pm 230$ a, respectively, with all ages falling at the higher end of the historical documented age. However, it is difficult to ascertain a maximum age of sand deposition from historical records.

For sample WEH2-2 from a sand layer, all calculated ages are in the historical documented age range (Table 5). They range from $70 \pm 10$ a to $120 \pm 30$ a but do not overlap within errors. The method from Fuchs and Lang (2001) and the leading edge model giving the youngest ages, whereas the oldest ages are obtained from the mean, $\mathrm{CAM}$ and $\mathrm{CAM}_{\mathrm{UL}}$.

The age results from sand layer WEH2-4 show a larger variation than in WEH2-2. Here the ages range from $90 \pm 10$ a to $250 \pm 90$ a. Ages calculated after the method from Fuchs and Lang (2001), leading edge model, and MAM-3 and MAM- $3_{U L}$ are in the historical documented age range (Fig. 3). The result from the median is overlapping within error to the historical documented age range. The mean, CAM and $\mathrm{CAM}_{\mathrm{UL}}$ are overestimating the historical documented age significantly.

For sample WEH2-5 from the sand at the base of section 2, the age results show the largest variation (Fig. 3, Table 5). They range from $110 \pm 20$ a to $260 \pm 270$ a. Ages calculated from the method after Fuchs and Lang (2001) and leading edge model are underestimating, whereas mean, $\mathrm{CAM}$ and $\mathrm{CAM}_{\mathrm{UL}}$ are overestimating the historical documented age range. Only the results from median, MAM-3 and MAM- $3_{U L}$ are in the historical documented

Table 5. Equivalent doses $\left(D_{E}\right)$ and ages (in years) calculated from different age models for the coarse grain quartz samples. The MAM-3uL ages are regarded as most reliable and highlighted in bold letters. Expected ages are derived from historical records. See text for more details. All OSL ages are related to the year of sampling in 2010 AD.

\begin{tabular}{|c|c|c|c|c|c|c|c|c|}
\hline & \multicolumn{2}{|c|}{ WEH1-2 } & \multicolumn{2}{|c|}{ WEH2-2 } & \multicolumn{2}{|c|}{ WEH2-4 } & \multicolumn{2}{|c|}{ WEH2-5 } \\
\hline & $D_{E}(G y)$ & Age (a) & $D_{E}(G y)$ & Age (a) & $D_{E}(G y)$ & Age (a) & $D_{E}(G y)$ & Age (a) \\
\hline Mean & $7.79 \pm 14.14$ & $6030 \pm 10970$ & $0.32 \pm 0.08$ & $120 \pm 30$ & $0.68 \pm 0.24$ & $250 \pm 90$ & $0.35 \pm 0.36$ & $260 \pm 270$ \\
\hline Median & $2.22 \pm 15.15$ & $1720 \pm 11740$ & $0.25 \pm 0.01$ & $100 \pm 10$ & $0.37 \pm 0.05$ & $140 \pm 20$ & $0.25 \pm 0.40$ & $190 \pm 300$ \\
\hline Fuchs and Lang (2001) & $1.08 \pm 0.10$ & $840 \pm 110$ & $0.18 \pm 0.01$ & $70 \pm 10$ & $0.24 \pm 0.02$ & $90 \pm 10$ & $0.15 \pm 0.02$ & $110 \pm 20$ \\
\hline Leading edge model ${ }^{*}$ & $1.06 \pm 0.28$ & $820 \pm 230$ & $0.19 \pm 0.02$ & $70 \pm 10$ & $0.27 \pm 0.07$ & $100 \pm 30$ & $0.15 \pm 0.04$ & $110 \pm 30$ \\
\hline $\mathrm{CAM}^{\dagger}$ & $3.21 \pm 0.45$ & $2490 \pm 420$ & $0.30 \pm 0.01$ & $110 \pm 10$ & $0.45 \pm 0.03$ & $170 \pm 10$ & $0.29 \pm 0.02$ & $220 \pm 20$ \\
\hline $\mathrm{CAMuL}^{\ddagger}$ & $6.88 \pm 1.38$ & $5330 \pm 1180$ & $0.30 \pm 0.02$ & $110 \pm 10$ & $0.58 \pm 0.09$ & $210 \pm 30$ & $0.34 \pm 0.06$ & $250 \pm 50$ \\
\hline MAM- $3^{\dagger}$ & $1.26 \pm 0.09$ & $980 \pm 110$ & $0.26 \pm 0.01$ & $100 \pm 10$ & $0.35 \pm 0.01$ & $130 \pm 10$ & $0.26 \pm 0.01$ & $190 \pm 20$ \\
\hline MAM-3uL ${ }^{\ddagger}$ & $1.35 \pm 0.06$ & $1050 \pm 110$ & $0.24 \pm 0.01$ & $90 \pm 10$ & $0.34 \pm 0.01$ & $130 \pm 10$ & $0.24 \pm 0.01$ & $180 \pm 20$ \\
\hline $\begin{array}{l}\text { Expected age } \\
\text { years before sampling } \\
\text { historical age period }\end{array}$ & \multicolumn{2}{|c|}{$\begin{array}{c}>749 a \\
>1261 A D\end{array}$} & \multicolumn{2}{|c|}{$\begin{array}{c}50-129 a \\
1881-1960 \mathrm{AD}\end{array}$} & \multicolumn{2}{|c|}{$\begin{array}{c}50-129 a \\
1881-1960 \mathrm{AD}\end{array}$} & \multicolumn{2}{|c|}{$\begin{array}{c}129-210 \mathrm{a} \\
1800-1881 \mathrm{AD}\end{array}$} \\
\hline
\end{tabular}

* Lepper and McKeever (2002); † Galbraith et al. (1999); ${ }^{\ddagger}$ Arnold et al. (2009); year of sampling 2010 AD. 
age range. But if taken the errors of the ages into account, all ages cover the historical documented age range.

\section{Age results for polymineral fine grain samples}

The fading corrected ages from the polymineral fine grain samples are overestimating the historical documented age by around 200 years (Table 6). Nevertheless, in section 1 the ages for WEH1-1 in stratigraphical order compared with WEH1-2 from the base of the section (Fig. 2). The ages from WEH1-1 range from $590 \pm 70$ a to $660 \pm 50$ a and overlapping within their errors. There is no significant difference between results of different age models.

In section 2 the ages from samples WEH2-1 and WEH2-3 are not in stratigraphical order (Fig. 3). The upper sample WEH2-1 is around 50 years older than the lower sample WEH2-3. Also compared with the age results for the coarse grain samples WEH2-2, WEH2-4 and WEH2-5, the polymineral fine grain samples are older. Ages from WEH2-1 are in the range from $300 \pm 20$ a to $330 \pm 40$ a and overlapping within errors. There is a slight difference between the age models. Mean, median, CAM and $\mathrm{CAM}_{\mathrm{UL}}$ are giving older ages than the method after Fuchs and Lang (2001), leading edge model, MAM-3 and

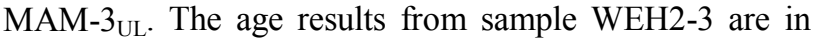
the range from $230 \pm 10$ a to $250 \pm 10$ a and overlapping within errors (Table 6). But still it can be seen that the results from mean, median, $\mathrm{CAM}$ and $\mathrm{CAM}_{\mathrm{UL}}$ are slightly higher than from the method after Fuchs and Lang (2001), leading edge model, MAM-3 and MAM- $3_{\mathrm{UL}}$.

\section{DISCUSSION}

\section{Coarse grain quartz}

From the depositional environment incomplete bleaching of the samples is expected and can be seen from the $\mathrm{D}_{\mathrm{E}}$ distributions (Fig. 7) and statistical parameters (Table 4). All coarse grain quartz samples show skewed $\mathrm{D}_{\mathrm{E}}$ distributions and high overdispersion values ranging from $37 \%$ to $116 \%$. The scatter and overdispersion values of the $\mathrm{D}_{\mathrm{E}}$ distribution differs for each sample indicating different amounts of incomplete bleaching. Interestingly, the overdispersion for the two event layers WEH2-2 and WEH2-4 are very different. The lower sand layer WEH2-4 has an overdispersion of $135 \%$ and the upper sand layer WEH2-2 an overdispersion of $42 \%$. The grains in sample WEH2-2 are much better bleached than for the other coarse grain quartz samples. For both event layers a similar process of transport and deposition can be assumed which would result in similar overdispersion values. It could be due to two flood events differing in strength and duration. Another possibility is that during the flood event of sample WEH2-2 the sand came from a source that was deposited briefly prior to the flooding, leaving less residual signal.

For incompletely bleached samples different age models have been developed to obtain the best estimate of the burial dose. These are the approach from Fuchs and Lang (2001), the leading edge model and the minimum age model (MAM). Other age models or statistical approaches like the approach from Murray et al. (1995), the lowest 5\% method from Olley et al. (1998) and bootstrapped likelihoods and Bayesian processing after Cunningham and Wallinga (2012) were not applied here.

Table 6. Equivalent doses $\left(D_{E}\right)$ and fading corrected ages (in years) calculated from different age models for the polymineral fine grain samples. Based on mathematical and statistical terms the CAM ${ }^{\dagger}$ ages regarded as most reliable (highlighted in bold letters). Fading correction was done following Huntley and Lamothe (2001). Expected ages are derived from historical records. See text for more details. All OSL ages are related to the year of sampling in 2010 AD.

\begin{tabular}{|c|c|c|c|c|c|c|c|c|c|}
\hline & \multicolumn{3}{|c|}{ WEH1-1 } & \multicolumn{3}{|c|}{ WEH2-1 } & \multicolumn{3}{|c|}{ WEH2-3 } \\
\hline & $D_{E}(G y)$ & $\begin{array}{l}\text { g-value } \\
\text { (\% per } \\
\text { decade) }\end{array}$ & Age (a) & $D_{E}(G y)$ & $\begin{array}{l}\text { g-value } \\
\text { (\% per } \\
\text { decade) }\end{array}$ & Age (a) & $D_{E}(G y)$ & $\begin{array}{l}\text { g-value } \\
\text { (\% per } \\
\text { decade) }\end{array}$ & Age (a) \\
\hline Mean & $1.78 \pm 0.20$ & $2.2 \pm 0.1$ & $590 \pm 70$ & $1.10 \pm 0.12$ & $2.3 \pm 0.1$ & $330 \pm 40$ & $0.88 \pm 0.04$ & $2.3 \pm 0.1$ & $250 \pm 20$ \\
\hline Median & $1.99 \pm 0.07$ & $2.2 \pm 0.1$ & $660 \pm 50$ & $1.09 \pm 0.05$ & $2.3 \pm 0.1$ & $330 \pm 20$ & $0.87 \pm 0.04$ & $2.3 \pm 0.1$ & $250 \pm 20$ \\
\hline Fuchs and Lang (2001) & $1.87 \pm 0.01$ & $2.2 \pm 0.1$ & $620 \pm 40$ & $1.02 \pm 0.01$ & $2.3 \pm 0.1$ & $300 \pm 20$ & $0.82 \pm 0.004$ & $2.3 \pm 0.1$ & $230 \pm 10$ \\
\hline Leading edge model $^{*}$ & $1.89 \pm 0.03$ & $2.2 \pm 0.1$ & $620 \pm 40$ & $1.03 \pm 0.04$ & $2.3 \pm 0.1$ & $310 \pm 20$ & $0.82 \pm 0.03$ & $2.3 \pm 0.1$ & $230 \pm 10$ \\
\hline $\mathrm{CAM}^{\dagger}$ & $2.00 \pm 0.01$ & $2.2 \pm 0.1$ & $660 \pm 40$ & $1.10 \pm 0.01$ & $2.3 \pm 0.1$ & $330 \pm 20$ & $0.88 \pm 0.01$ & $2.3 \pm 0.1$ & $250 \pm 10$ \\
\hline $\mathrm{CAMUL}^{\ddagger}$ & $2.00 \pm 0.01$ & $2.2 \pm 0.1$ & $660 \pm 40$ & $1.10 \pm 0.01$ & $2.3 \pm 0.1$ & $330 \pm 20$ & $0.88 \pm 0.01$ & $2.3 \pm 0.1$ & $250 \pm 10$ \\
\hline MAM-3 ${ }^{\dagger}$ & $1.96 \pm 0.01$ & $2.2 \pm 0.1$ & $650 \pm 40$ & $1.05 \pm 0.01$ & $2.3 \pm 0.1$ & $310 \pm 20$ & $0.84 \pm 0.01$ & $2.3 \pm 0.1$ & $240 \pm 10$ \\
\hline MAM-3UL ${ }^{\ddagger}$ & $1.96 \pm 0.01$ & $2.2 \pm 0.1$ & $650 \pm 40$ & $1.03 \pm 0.01$ & $2.3 \pm 0.1$ & $310 \pm 20$ & $0.83 \pm 0.01$ & $2.3 \pm 0.1$ & $240 \pm 10$ \\
\hline $\begin{array}{l}\text { Expected age } \\
\text { years before sampling } \\
\text { historical age period }\end{array}$ & & $\begin{array}{c}0-420 \text { a } \\
1590-2010 \text { AD }\end{array}$ & & & $\begin{array}{c}50-129 a \\
1881-1960 \mathrm{AD}\end{array}$ & & & $\begin{array}{c}50-129 a \\
1881-1960 \mathrm{AD}\end{array}$ & \\
\hline
\end{tabular}

*Lepper and McKeever (2002); † Galbraith et al. (1999); ¥ Arnold et al. (2009); year of sampling 2010 AD 
The approach from Fuchs and Lang (2001), the leading edge model (Lepper and McKeever, 2002) and the minimum age model, both logged and unlogged, give ages which are in the historical documented age range. Although these methods are all based on taking the lowest $\mathrm{D}_{\mathrm{E}}$ into account there are significant differences between each model. The youngest ages are resulting from the approach from Fuchs and Lang (2001). Slightly older ages are obtained with the leading edge model. Both models, however, tend to underestimate the expected age, which is obvious for samples WEH2-5 and WEH1-2 where the result is on the lower limit of the historical documented age. The approach from Fuchs and Lang (2001) was developed for samples with a limited number of aliquots. In their study, only 10 aliquots per sample were measured due to very low amount of available sample material. The use of the dose recovery test results as indicator for bleaching behavior is a good way to account for OSL properties. For a limited amount of $D_{E}$ values, this approach might work well as shown by Fuchs and Lang (2001). But for larger data sets it becomes problematic as it is solely based on dose recovery test and does not take the $\mathrm{D}_{\mathrm{E}}$ distribution itself into account. Depending on the dose recovery test, the threshold for samples with good bleaching behavior will be low, which will result in taking only the few lowest $\mathrm{D}_{\mathrm{E}}$ values for age calculation. In our study, for sample WEH2-5, only the lowest $10 \mathrm{D}_{\mathrm{E}}$ values were taken with this method and lead to clear underestimation of the expected age. For sample WEH2-4, only the lowest $4 \mathrm{D}_{\mathrm{E}}$ values (out of 85 accepted aliquots) were taken. In the work from Fuchs and Lang (2001) it is not clearly stated how many aliquots should be used for the dose recovery test. Depending on the number of aliquots used the threshold changes. It can be expected that the standard deviation in the dose recovery will be lower when using more aliquots which then reduces the threshold and the amount of aliquots chosen later for the age calculation. Another practical issue is that measuring the same amount of aliquots for the dose recovery test as later for the SAR measurements requires much more machine time.

The results obtained from the leading edge model are almost similar as the approach from Fuchs and Lang (2001). In this model it is assumed that the lowest $D_{E}$ values representing the best bleached grains in a distribution. Based on the fitting of the Gaussian equation to the rising limb, the paleodose is always lower than the $D_{\mathrm{E}}$ in the first main peak of the histogram giving the tendency toward age underestimation. For sample WEH2-5, the age obtained from the leading edge model is well below from the historical documented age and for sample WEH1-2 the obtained age is at the lower boundary of the historical documented age.

The results from the minimum age model are all in the historical documented age range. Compared with the CAM, the differences between the results from the MAM-3 and MAM- $3_{\mathrm{UL}}$ are small and overlapping within errors. For samples WEH2-2, WEH2-4 and WEH2-5, the MAM- $3_{\mathrm{UL}}$ gives slightly younger ages than from the MAM-3. This difference is also observed from Arnold et al. (2009). Our results show that the MAM-3 and MAM- $3_{\mathrm{UL}}$ ages are higher than from Fuchs and Lang (2001) and leading edge model. This is the opposite of the observation in Arnold et al. (2009) where the leading edge model gave ages which are older than from minimum age models. In the study of Lauer et al. (2011) fluvial sediments from a Roman harbor in Cologne (Germany) were investigated and different statistical approaches were used to calculate the OSL age. The method from Fuchs and Lang (2001) and the leading edge model from Lepper and McKeever (2002) gave results which are consistent with the expected historical age, whereas the result from the MAM-3 underestimates the expected historical age.

\section{Polymineral fine grain samples}

The $D_{E}$ distributions of the polymineral fine grain samples WEH1-1, WEH2-1 and WEH2-3 are all unimodal and the statistical parameters are indicating a normal distribution, which is typical for fully bleached samples as, for example, dune sands (Alappat et al., 2011; Kunz et al., 2010). Based on the fluvial deposition of the sediments, incomplete bleaching of the polymineral fine grain samples has to be expected but cannot be detected from the $\mathrm{D}_{\mathrm{E}}$ distribution. The reason for that are the averaging effects of the large multi grain aliquots masking the partial bleaching signature. Each aliquot contains between $1.1 \times 10^{6}$ and $2.2 \times 10^{7}$ grains with different levels of bleaching. The number of grains on an aliquot is an estimate based on the assumption that each grain is a sphere having a density of $2.65 \mathrm{~g} \mathrm{~cm}^{-3}$ and with diameters ranging from $4 \mu \mathrm{m}$ to $11 \mu \mathrm{m}$. Each aliquot contains $2 \mathrm{mg}$ sample distributed on the complete area of the disc. Averaging effects of polymineral fine grain samples from fluvial samples are observed in several studies (Preusser, 1999; Urban et al., 2011b). Only the overestimation of the expected age gives a hint that the samples are not fully bleached. But without any idea about the depositional age, OSL dating results of fluvial deposited polymineral fine grain samples should be treated with caution.

For each sample, the ages from each age model are similar and overlapping within error ranges. In contrast to the results of the logged and unlogged central and minimum age models for the coarse grain samples, there is no difference between logged and unlogged CAM and MAM for the polymineral fine grain samples. For sample WEH1-1, all $D_{E}$ values $>1$ Gy and the $\log D_{E}$ values are positive. It is the same for sample WEH2-1 where all $\mathrm{D}_{\mathrm{E}}$ values just larger than $1 \mathrm{~Gy}$, except for one aliquot with $0.950 \mathrm{~Gy}$. Its contribution, however, is too small that it has any effect on the CAM or MAM results. For sample WEH2-3, all $D_{\mathrm{E}}$ values just lower than $1 \mathrm{~Gy}$, except for one aliquot with $1.016 \mathrm{~Gy}$. All $\log \mathrm{D}_{\mathrm{E}}$ values are negative and the only positive value also has no significant influence on the result. 


\section{Age results compared with historical documented river evolution}

For the coarse grain quartz samples the most reliable ages are obtained using the unlogged minimum age model MAM-3 $3_{\mathrm{UL}}$. For sample WEH1-2, from section 1 located on the Old Foreland, the results from the leading edge model and the approach from Fuchs and Lang (2001) give deposition ages of around 830 years ago. This is close to the period of construction of the dam 749 years ago. Considering the uncertainties of the results, they are overlapping with the historical documented age and the leading edge model give younger values. From the historical documents it is known that the dam was located along a levee which is today the border between the Old Foreland and the Young Foreland (Greve, 1999). This means that the northern river bank was in a similar location than the present river bank. Section 1 is located about $300 \mathrm{~m}$ away from the previous dam and the river bank, respectively. It is very unlikely that the river bed shifted within about 80 years by $300 \mathrm{~m}$. There are also no reports that the river was artificially relocated during construction of the dam. The depositional age given by the MAM- $3_{\mathrm{UL}}$ with $1050 \pm 110$ years ago is apparently more realistic. With this age the river would have changed the bed to a more southern position with a mean rate of $1.5 \mathrm{~m}$ per year. A natural migration rate of this order was also observed by Rommel et al. (2012), who reconstructed the migration of the German part of the Elbe River over the last 200 years. They found that the natural migration of meandering part the river varies between $0.5 \mathrm{~m}$ to $7.5 \mathrm{~m}$ per year due to frequent occurring strong floods along the Elbe River.

Section 2 is located in a position which experienced different periods of sedimentation and erosion which are documented over the last 284 years (Fig. 4). Around $1800 \mathrm{AD}$ more sediment was accumulated at the northern river bank. River engineering and construction of groins supported the accumulation of this sand. From 1843 AD until $1881 \mathrm{AD}$ more groins were constructed (Weniger, 2010) so that more sediment could be accumulated and the river changed its bed to a southward direction (Fig. 4). Since $1843 \mathrm{AD}$ the area were section 2 is located became finally land (Fig. 1d). The result of the MAM- $3_{\mathrm{UL}}$ with $180 \pm 20$ years for sample WEH2-5 falls into a period (1810 AD to $1850 \mathrm{AD}$ ) were the location of section 2 changed from an active river channel to land. This result could mark the beginning of sedimentation for that part of the Younger Foreland. The depositional ages from the leading edge model and Fuchs and Lang (2001) are too young. With a depositional age of $110 \pm 30$ years and $110 \pm 20$ years, respectively, they are in a time period (1900 AD) were the location was definitely land (Fig. 1). Even if the uncertainties are considered the age of deposition is still in a time (1870-1880 AD) were the area was already mapped as land (Fig. 1).

The sand layers in section 2 are related to flood events which occur frequently along the Elbe River mostly in
March and April. Floods are driven by snow melt in mountain areas in the border area of Germany, Poland and Czech Republic as well as strong rainfall in the catchment areas of the tributary rivers. In the gauge station Neu Darchau, which is located $20 \mathrm{~km}$ downstream of the study area, major flood events with a discharge of more than $3000 \mathrm{~m}^{3} / \mathrm{s}$ were documented in the years 1881 , 1895, 1920, 1940, 1941, 1947, 1975, 1982, 1988, 2002, 2006 and 2011 (IKSE, 2004; IKSE, 2012). During these events the water level in the study area rises up to 3.6 meters above mean water level which makes deposition of sand possible. The recurrence interval for events with a discharge of 3000 to $4000 \mathrm{~m}^{3} / \mathrm{s}$ is between 10 and 50 years (Helms et al., 2002). As the uncertainties of the OSL age results for samples WEH2-2 and WEH2-4 are in the same order as the recurrence interval, it is difficult to relate them to one of these events and multiple solutions are possible. Based on the heavy metal distribution in section 2 (Urban et al., 2011a) deposition of the sand layers happened before 1960 AD. Hence, events from $1881 \mathrm{AD}$ to $1947 \mathrm{AD}$ could be possible. The results from the MAM-3 $3_{\mathrm{UL}}$ coincide with the events from $1881 \mathrm{AD}$ and $1920 \mathrm{AD}$ and do not overlap with their uncertainties with other major flood events. In contrast the leading edge model gives only one age which coincides with the flood event in $1940 \mathrm{AD}$. For the lower sand layer (WEH2-4) the age does not correlate with any event. Considering the uncertainties of the ages from the leading edge model, then they span the whole range of events making these results imprecise. The results from the approach of Fuchs and Lang (2001) coincide with the events from $1920 \mathrm{AD}$ and $1940 \mathrm{AD}$. The uncertainties overlap only for the younger sample (WEH2-2) with other flood events in $1941 \mathrm{AD}$ and $1947 \mathrm{AD}$. As the method from Fuchs and Lang (2001) has a tendency for age underestimation and the ages from the leading edge model have too large uncertainties, the results from the MAM- $3_{\mathrm{UL}}$ are considered as the most likely age of deposition of the flood plain layers.

The age results of the polymineral fine grain samples overestimating the historically documented ages. In section 1 the depositional age for the floodplain deposits from sample WEH1-1 span a time period from $1300 \mathrm{AD}$ to $1490 \mathrm{AD}$, if all ages including their uncertainties are considered. This falls into the time when the area of the Old Foreland was protected by a dam. In section 2 on the Young Foreland the ages, including their uncertainties, for sample WEH2-1 span a time of deposition from 1640 $\mathrm{AD}$ to $1730 \mathrm{AD}$ and for sample WEH2-3 $1740 \mathrm{AD}$ to 1790 AD. From historical documents it is known that the area of section 2 became finally land in 1881 AD (Fig. 1). Before $1881 \mathrm{AD}$ it underwent different periods of sedimentation and erosion (Fig. 4). Hence, deposition of the floodplain sediments is very unlikely at the time given by the OSL dating results. 


\section{CONCLUSION}

In this study we investigated fluvial sediments from the Elbe River in North Germany. For each sample different age models have been used to calculate the age of deposition and compared with the historical documented river evolution. Following conclusions can be drawn from this study:

- Our study showed that OSL dating of fluvial samples with incomplete bleaching can give reliable results when appropriate age models are used. This will help for future OSL studies along the Elbe River to reconstruct the river evolution beyond the historical documented period.

- For the coarse grain quartz samples, all age models which are based on taking the lowest $\mathrm{D}_{\mathrm{E}}$ values from a skewed distribution into account, give results which are consistent with the historical documented age.

- OSL ages for coarse grain quartz samples calculated from the MAM- $3_{\mathrm{UL}}$, agree well with the historical documented evolution of the Elbe River. Results from the approach of Fuchs and Lang (2001) show a tendency for age underestimation. Ages calculated using the leading edge model show higher uncertainties and making them less precise.

- Ages for incomplete bleached coarse grain samples obtained by the mean, median, CAM or $\mathrm{CAM}_{\mathrm{UL}}$ overestimate the historical documented age or giving ages with high errors making the results imprecise and unreliable.

- The results from the investigated polymineral fine grain samples from floodplain deposits overestimate the historical documented ages significantly due to not detectable incomplete bleaching, OSL dating using polymineral fine grain samples from fluvial environments should be done with caution, especially when working with young sediments.

\section{ACKNOWLEDGEMENTS}

The authors thank the Federal Institute for Hydrology in Germany for providing stream gauge data of the Elbe River. We acknowledge the Netherlands Centre for Luminescence dating for providing free MATLAB scripts for MAM-3 and MAM-3 ${ }_{U L}$ calculation. Will Mounger is thanked for refining the English. We thank Ben and the Friday-PhD-Group for fruitful and encouraging discussions.

\section{REFERENCES}

Aitken MJ, 1985. Thermoluminescence Dating. London, Academic Press: $359 \mathrm{pp}$

Aitken MJ, 1998. An introduction to optical dating. Oxford, Oxford University Press: 267pp.

Alappat L, Frechen M, Ramesh R, Tsukamoto S and Srinivasalu, S, 2011. Evolution of late Holocene coastal dunes in the Cauvery del- ta region of Tamil Nadu, India. Journal of Asian Earth Sciences 42: 381-397, DOI 10.1016/j.jseaes.2011.05.019.

Arnold LJ, Roberts RG, Galbraith RF and DeLong SB, 2009. A revised burial dose estimation procedure for optical dating of young and modern-age sediments. Quaternary Geochronology 4: 306-325, DOI 10.1016/j.quageo.2009.02.017.

Auclair M, Lamothe M and Huot S, 2003. Measurement of anomalous fading for feldspar IRSL using SAR. Radiation Measurements 37: 487-492, DOI 10.1016/S1350-4487(03)00018-0.

Bailey RM and Arnold LJ, 2006. Statistical modelling of single grain quartz $\mathrm{D}_{\mathrm{E}}$ distributions and an assessment of procedures for estimating burial dose. Quaternary Science Reviews 25: 2475-2502, DOI 10.1016/j.quascirev.2005.09.012.

Cunningham AC and Wallinga J, 2010. Selection of integration time intervals for quartz OSL decay curves. Quaternary Geochronology 5: 657-666, DOI 10.1016/j.quageo.2010.08.004

Cunningham AC and Wallinga J, 2012. Realizing the potential of fluvial archives using robust OSL chronologies. Quaternary Geochronology 12: 98-106, DOI 10.1016/j.quageo.2012.05.007.

Ditlefsen C, 1992. Bleaching of K-feldspars in turbid water suspensions: a comparison of photo- and thermoluminescence signals. Quaternary Science Reviews 11: 33-38, DOI 10.1016/02773791(92)90039-B.

Duller GAT, 2003. Distinguishing quartz and feldspar in single grain luminescence measurements. Radiation Measurements 37: 161165, DOI 10.1016/S1350-4487(02)00170-1.

Duller GAT, 1994. Luminescence dating of poorly bleached sediments from Scotland. Quaternary Science Reviews 13: 521-524, DOI 10.1016/0277-3791(94)90070-1.

Duller GAT, 2008. Single-grain optical dating of Quaternary sediments: why aliquot size matters in luminescence dating. Boreas 37: 589612, DOI 10.1111/j.1502-3885.2008.00051.x.

Ehlers J, Astakhov V, Gibbard PL, Mangerud J and Svendsen JI, 2007. Late Pleistocene glaciations in Europe. In: Elias, S.A. (Ed.), Encyclopedia of Quaternary science. Amsterdam, Elsevier: pp.10851095.

Fabel E, 2001. Chronik des Dorfes Wehningen (Chronicles of the village Wehningen) . unpublished (in German).

Fiebig M and Preusser F, 2007. Investigating the amount of zeroing in modern sediments of River Danube, Austria. Quaternary Geochronology 2: 143-149, DOI 10.1016/j.quageo.2006.09.001.

Fuchs M and Lang A, 2001. OSL dating of coarse-grain fluvial quartz using single-aliquot protocols on sediments from NE Peloponnese, Greece. Quaternary Science Reviews 20: 783-787, DOI 10.1016/S0277-3791(00)00040-8.

Frechen M, Schweitzer U and Zander A, 1996. Improvements in sample preparation for the fine grain technique. Ancient TL 14: 15-17.

Galbraith RF and Green PF, 1990. Estimating the component ages in a finite mixture. Nuclear Tracks and Radiation Measurements 17: 197-206, DOI 10.1016/1359-0189(90)90035-V.

Galbraith RF and Laslett GM, 1993. Statistical models for mixed fission track ages. Nuclear Tracks and Radiation Measurements 21: 459470, DOI 10.1016/1359-0189(93)90185-C.

Galbraith RF, Roberts RG, Laslett GM, Yoshida H and Olley JM, 1999. Optical dating of single and multiple grains of quartz from Jinmium Rock Shelter, Northern Australia: Part I, experimental design and statistical models. Archaeometry 41: 339-364, DOI 10.1111/j.1475-4754.1999.tb00988.x.

Galbraith RF and Roberts RG, 2012. Statistical aspects of equivalent dose and error calculation and display in OSL dating: An overview and some recommendations. Quaternary Geochronology 11: 1-27, DOI 10.1016/j.quageo.2012.04.020.

Genieser K, 1962. Neue Daten zur Flußgeschichte der Elbe (Zielsetzung und Ergebnisse von Kartierungsbohrungen und -schürfen im Pleistozän des Raumes zwischen Dresden und Berlin). (New data about the river development of the Elbe (Mission and results of mapping Pleistocene deposits using drillings and outcrops in the area between Dresden and Berlin)) E\&G: Quaternary Science Journal 13: 141-156 (in German), DOI 10.3285/eg.13.1.10. 
Geyh MA, 2008. The handling of numerical ages and their random uncertainties. E\&G: Quaternary Science Journal 57(1-2): 239252, DOI 10.3285/eg.57.1-2.10.

Götz R, Bauer O-H, Friesel P, Herrmann T, Jantzen E, Kutzke M, Lauer R, Paepke O, Roch K, Rohweder U, Schwartz R, Sievers S and Stachel B, 2007. Vertical profile of PCDD/Fs, dioxin-like PCBs, other PCBs, PAHs, chlorobenzenes, DDX, HCHs, organotin compunds and chlorinated ethers in dated sediment/soil cores from floodplains of the river Elbe, Germany. Chemosphere 67B (3): 592-603, DOI 10.1016/j.chemosphere.2006.09.065.

Greve D, 1999. Das Amt Neuhaus und seine Nachbarn: Grenzbuch aus dem Jahr 1591; Generalkarte der Rögnitz-Sude-Regulierung 1789. (The Neuhaus district and its neighbors: Land register from the year 1591; General map of the Rögnitz-Sude-river control 1789.) Landkreis Lüneburg, Lüneburg. (in German).

Guerin G, Mercier N and Adamiec G, 2011. Dose-rate conversion factors: update. Ancient TL 29: 5-8.

Helms M, Büchele B, Merkel U and Ihringer J, 2002. Statistical analysis of the flood situation and assessment of the impact of diking measures along the Elbe (Labe) river. Journal of Hydrology: 267, 94-114, DOI 10.1016/S0022-1694(02)00143-9.

Huntley DJ and Lamothe M, 2001. Ubiquity of anomalous fading in Kfeldspars and the measurement and correction for it in optical dating. Canadian Journal of Earth Sciences 38: 1093-1106, DOI 10.1139/e01-013.

IKSE. International Comission for the Protection of the Elbe River. Web site: <http://www.ikse-mkol.org/index.php?id=22\&L=2>. Accessed 2013 April 15.

IKSE, 2004. Dokumentation des Hochwassers vom August 2002 im Einzugsbgebiet der Elbe. Magdeburg, Internationale Kommission zum Schutz der Elbe (IKSE): 207pp (Documentation of the flood in the catchment of the Elbe River from August 2002. Magdeburg, International Commission for the Protection of the Elbe River), in German.

IKSE, 2012. Abschlussbericht über die Erfüllung des „Aktionsplans Hochwasserschutz Elbe“ 2003-2011. Magdeburg, Internationale Kommission zum Schutz der Elbe (IKSE): 67pp (Final report about the accomplishment of the ,Action plan for floodprotection along the Elbe River' 2003-2011. Magdeburg, International Commission for the Protection of the Elbe River), in German.

KLIMZUG-NORD. Regional strategies concerning climate changes in the metropolitan area of Hamburg. <http://www.klimzugnord.de/>

Kunz A, Frechen M, Ramesh R and Urban B, 2010. Periods of recent dune sand mobilisation in Cuddalore, Southeast India. Zeitschrift der Deutschen Gesellschaft für Geowissenschaften 161: 353-368, DOI 10.1127/1860-1804/2010/0161-0353.

Lauer T, Bonn R, Frechen M, Fuchs MC, Trier M and Tsukamoto S, 2011. Geoarchaeological studies on Roman time harbour sediments in Cologne - Comparison of different OSL dating techniques. Geochronometria 38: 341-349, DOI 10.2478/s13386-0110020-y.

Lepper K and McKeever SWS, 2002. An objective methodology for dose distribution analysis. Radiation Protection Dosimetry 101: 349-352.

Madsen AT, Murray AS, Andersen TJ, Pejrup M and Breuning-Madsen $\mathrm{H}, 2005$. Optically stimulated luminescence dating of young estuarine sediments: a comparison with ${ }^{210} \mathrm{~Pb}$ and ${ }^{137} \mathrm{Cs}$ dating. Marine Geology 214: 251-268, DOI 10.1016/j.margeo.2004.10.034.

Mauz B and Lang A, 2004. The dose rate of beta sources for optical dating applications: A comparison between fine silt and fine sand quartz. Ancient TL 22: 45-48.

Mauz B, Packman S and Lang A, 2006. The alpha effectiveness in siltsized quartz: New data obtained by single and multiple aliquot protocols. Ancient TL 24: 47-52.

Murray AS, Olley JM and Caitcheon GG, 1995. Measurement of equivalent doses in quartz from contemporary water-lain sediments using optically stimulated luminescence. Quaternary Science Reviews 14: 365-371, DOI 10.1016/0277-3791(95)00030-5.
Murray AS and Olley JM, 2002. Precision and accuracy in the optically stimulated luminescence dating of sedimentary quartz: a status review. Geochronometria 21: 1-16.

Murray AS and Wintle AG, 2000. Luminescence dating of quartz using an improved single-aliquot regenerative-dose protocol. Radiation Measurements 32: 57-73, DOI 10.1016/S1350-4487(99)00253-X.

Murray AS and Wintle AG, 2003. The single aliquot regenerative dose protocol: potential for improvements in reliability. Radiation Measurements 37: 377-381, DOI 10.1016/S1350-4487(03)00053-

Murray AS, Buylaert JP, Thomsen KJ and Jain M, 2009. The effect of preheating on the IRSL signal from feldspar. Radiation Measurements 44: 554-559, DOI 10.1016/j.radmeas.2009.02.004.

Olley JM, Murray A and Roberts RG, 1996. The effects of disequilibria in the uranium and thorium decay chains on burial dose rates in fluvial sediments. Quaternary Science Reviews 15: 751-760, DOI 10.1016/0277-3791(96)00026-1.

Olley J, Caitcheon G and Murray A, 1998. The distribution of apparent dose as determined by optically stimulated luminescence in small aliquots of fluvial quartz: implications for dating young sediments. Quaternary Science Reviews 17: 1033-1040, DOI 10.1016/S02773791(97)00090-5.

Olley JM, De Deckker P, Roberts RG, Fifield LK, Yoshida H and Hancock G, 2004. Optical dating of deep-sea sediments using single grains of quartz: a comparison with radiocarbon. Sedimentary Geology 169: 175-189, DOI 10.1016/j.sedgeo.2004.05.005.

Puffahrt O, 1999. Geschützte Elbmarsch: zur Geschichte des Neuhauser Deichverbandes. (Protected Elbmarsh: The history of the dike union of Neuhaus.) Landkreis Lüneburg, Lüneburg (in German).

Prescott JR and Stephan LG, 1982. The contribution of cosmic radiation to the environmental dose for thermoluminescent dating - Latitude, altitude and depth dependences. PACT 6: 17-25.

Prescott JR and Hutton JT, 1994. Cosmic ray contributions to dose rates for luminescence and ESR dating: large depths and long-term time variations. Radiation Measurements 23: 497-500, DOI 10.1016/1350-4487(94)90086-8.

Preusser F, 1999. Luminescence dating of fluvial sediments and over bank deposits from Gossau, Switzerland: fine grain dating. Ouaternary Science Reviews 18: 217-222, DOI 10.1016/S02773791(98)00054-7.

Rees-Jones J and Tite MS, 1997. Optical dating results for british archaeological sediments. Archaeometry 39: 177-187, DOI 10.1111/j.1475-4754.1997.tb00797.x.

Rendell HM, Webster SE and Sheffer NL, 1994. Underwater bleaching of signals from sediment grains: New experimental data. Quaternary Science Reviews 13: 433-435, DOI 10.1016/02773791(94)90055-8.

Rittenour T, 2008. Luminescence dating of fluvial deposits: applications to geomorphic, palaeoseismic and archaeological research. Boreas 37: 613-635, DOI 10.1111/j.1502-3885.2008.00056.x.

Rommel J, Hatz M and Weniger T, 2012. Verlaufsrekonstruktion der deutschen Binnenelbe um 1830/1850 zur Bearbeitung hydromorphologischer Fragestellungen im Zuge der Umsetzung europäischer Rahmen- und Managementrichtlinien. (Reconstructing the stream course of the German Elbe for the years 1830/1850 to address hydromorphological issues regarding application of European framework and management directives). Hydrologie und Wasserbewirtschaftung 56(6): 306-319 (in German with abstract, conclusions and figure captions in English), DOI 10.5675/HyWa 2012,6 2 .

Urban B, Krüger F, Weniger T, Prüter J, Keienburg T, Lang F and Graf M, 2011a. Auenböden der Elbe als Archiv für die Stoffdynamik im Einzugsgebiet. (Fluvisols of the Elbe River as archives for element dynamics in the catchment area). Deutsche Bodenkundliche Gesellschaft - Exkursionsführer 114: $42-59$ (in German).

Urban B, Kunz A and Gehrt E, 2011b. Genesis and dating of Late Pleistocene-Holocene soil sediment sequences from the Lüneburg Heath, Northern Germany. E\&G:Quaternary Science Journal 60: 164-184, DOI 10.3285/eg.60.1.01. 
Vermeesch P, 2009. RadialPlotter: a Java application for fission track, luminescence and other radial plots, Radiation Measurements 44(4): 409-410, DOI 10.1016/j.radmeas.2009.05.003.

Wallinga J, 2002. Optically stimulated luminescence dating of fluvial deposits: a review. Boreas 31: 303-322, DOI 10.1111/j.15023885.2002.tb01076.x.

Wallinga J, Bos AJJ, Dorenbos P, Murray AS and Schokker J, 2007. A test case for anomalous fading correction in IRSL dating. Quaternary Geochronology 2: 216-221, DOI 10.1016/j.quageo.2006.05.014.

Wallinga $\mathrm{J}$ and Bos IJ, 2010. Optical dating of fluvio-deltaic clastic lake-fill sediments - A feasibility study in the Holocene Rhine delta (western Netherlands). Quaternary Geochronology 5: 602-610, DOI 10.1016/j.quageo.2009.11.001.

Wallinga J, Hobo N, Cunningham AC, Versendaal AJ, Makaske B and Middelkoop H, 2010. Sedimentation rates on embanked floodplains determined through quartz optical dating. Quaternary Geochronology 5: 170-175, DOI 10.1016/j.quageo.2009.01.002.

Weniger T, 2010. Untersuchungen zur Auenbodenentwicklung und zu ausgewählten Standorteigenschaften in der Mäanderschleife Wehningen - Ein Beitrag zur zukunftsfähigen Gestaltung der Kulturlandschaft an der unteren Mittelelbe. (Investigating the development of fluvisols and soil characteristics in the meander of Wehningen - A contribution for sustainable development of the cultural landscape along the middle Elbe river). Diploma thesis, Leuphana University, Lüneburg (in German). Unpublished.

Wintle AG and Murray AS, 2006. A review of quartz optically stimulated luminescence characteristics and their relevance in singlealiquot regeneration dating protocols. Radiation Measurements 41:
369-391, DOI 10.1016/j.radmeas.2005.11.001.

Woldstedt P, 1956. Die Geschichte des Flußnetzes in Norddeutschland und angrenzenden Gebieten. (History of the drainage network in North-Germany and adjacent areas). E\&G: Quaternary Science Journal 7: 5-12 (in German), DOI 10.3285/eg.07.1.01.

Map from 1729 AD: 'Karte der Elbe von Laase - Jasebeck (mit Gelände)' [Map of the Elbe River at Laase-Jasebeck (with topography)], 1:15,000, mapped by Michaelsen, Hauptstaatsarchiv Hannover [Federal Archive of the State of Lower Saxony in Hanover, Germany], collection of maps: number $31 \mathrm{~d} / 15 \mathrm{pg}$.

Map from 1775 AD: 'Kurhannoversche Landesaufnahme, 1:25.000, Blatt 75 Hitzacker' [Topographic surveying of the Electorate of Brunswick-Lüneburg, 1:25,000, sheet 75 Hitzacker], Landesamt für Geoinformation und Landentwicklung Niedersachsen [Mapping agency of the State of Lower Saxony in Hanover, Germany].

Map from 1800 AD: 'Plan des Elbstromes in den lüneburgischen Ämtern Dannenberg u. Hitzacker und dem adeligen Gerichte Jasebeck, dem lauenburgischen Amte Neuhaus und dem adelichen Gerichte Wehningen'. [Map of the Elbe River in the districts Dannenberg \& Hitzacker and the noble estate Jasebeck of the county of Lüneburg, the district of Neuhaus and noble estate Wehningen of the county of Lauenburg.] mapped 1799 and 1800, proofed 1803 by G.H. Buchholz, private collection of O.Puffahrt, Lüneburg (Germany).

Map from 1881 AD: 'Preußische Landesaufnahme, 1:25.000, Blatt 2832 Dannenberg', [Topographic surveying of Prussia, 1:25,000, sheet 2832 Dannenberg] Landesamt für Geoinformation und Landentwicklung Niedersachsen [Mapping agency of the State of Lower Saxony in Hanover, Germany]. 